\title{
Summary of the 2004 CFD Validation Workshop on Synthetic Jets and Turbulent Separation Control
}

\author{
C. L. Rumsey*'T. B. Gatski† W. L. Sellers III‡ V. N. Vatsał S. A. Viken \\ NASt Langley Research C'nter. Hampton. IA 23681-2199. TSA
}

\begin{abstract}
A CFD validation workshop for synthetic jets and turbulent separation control (CFDVAL2004) was held in Williamsburg. Virginia in March 2004. Three cases were investigated: synthetic jet into quiescent air. synthetic jet into a turbulent boundary layer crossflow. and flow over a hump model with no-flow-control. steady suction. and oscillatory control. This paper is a summary of the CFD results from the workshop. Although some detailed results are shown. mostly a broad viewpoint is taken, and the CFD stateof-the-art for predicting these types of flows is evaluated from a general point of view. Overall. for synthetic jets. CFD can only qualitatively predict the flow pinysics, but there is some uncertainty regarding how to best model the unsteady boundary conditions from the experiment consistently. As a result. there is wide variation among CFD results. For the hump flow. CFD as a whole is capable of predicting many of the particulars of this flow provided that tunnel blockage is accounted for, but the length of the separated region compared to experimental results is consistently overpredicted.
\end{abstract}

\section{Introduction}

The study of separation control throngh the use of blowing, suction, and synthetic jets has been an active field of research for some time now. ${ }^{1}$ Many experimental and theoretical papers (only a few of which are referenced here) have been published on the subject. ${ }^{2-b}$ The review article by (ireenblatt and Wygnanski ${ }^{7}$ lists many additional references. There has also been a recent increase of attention paid to the field by the American Institute of Aeronautirs and Astronautics (AIAA), which held its first Flow ('ontrol ('onference in June 2002 in St. Louis. Missouri, and now sponsors it as a continuing biennial series.

Computational methods have also been used extensively for computing synthetic jet flows. Only a few examples are referenced here ${ }^{8-13}$ However, to our knowledge most ('FD efforts have been somewhat isolated. so it has been difficult to make an assessment of the state-of-the-art as a whole. In order to more broadly assess the current capabilities of different classes of computational methodologies, the time appeared to be ripe to hold a workshop for which many participants would compute the same flow control test cases. To this end, the CFD Validation of Synthetic Jets and Turbulent Separation Control (CFDVAL2004) workshop was held in Williamsburg, Virginia in March 2004. ${ }^{14}$ Three different test cases, all of which were carried out experimentally at NASA Langley Research Center, exercised various aspects related to the flow physics of separation control.

\footnotetext{
* Senior Research Scientist. Computational Modeling and Simulation Branch, Mail Stop 128, Associate Fellow AlAA.

tSenior Research Scientist, Computational Modeling and Simulation Branch. Mail Stop 128. Member AIAA.

${ }^{\ddagger}$ Branch Head. Flow Physics and Control Branch, Mail Stop 170, Associate Fellow AIAA.

$\$$ Senior Research Scientist, Computational Modeling and Simulation Branch, Mail Stop 128. Senior Member AlAA.

Technical Assistant of Systems Technology Development. ASPO - Small Aircraft Transportation Systems. Mail Stop 916.

Copyright $(9) 2004$ by the American Institute of Aeronautics and Astronautics. Inc. The U.S. Government has a rovalty-free license to exercise all rights under the copyright claimed herein for Governmental purposes. All other rights are reserved by the copyright owner.
} 
This paper is a summary report of the overall (CD results from the (FDVAL2004 workshop. It does not dirertly address technical issues associated with the experiments themselves, excejt as they relate to the (FI) modeling of the flows. Technical papers describing the experiments are alwo available. ${ }^{15-17}$ This paper is organized as follows. First, a brief description of the workshop is given, including an ovcrall description of the three test cases. Then, a summary of results from each of the three test cases is presented. Finally, the paper closes with summary and conclusions.

\section{The CFDVAL2004 Workshop}

The (FDVAL2004 workshop) was structured similarly to the series of Refined 'Turbulence Modeling workshops sponsored by the European Research (onmunity on Flow, Turbulence, and (ombustion (ERCOFTA('). The 10th such workshop was held in October 2002 in Poitiers. France. Although not formally a part of the European series, (FDVAL2004 was held in association with the ERCOFTA(: organization, and representative members from that organization contributed to the workshop. (FDVAL2004 was also associated with the Air Force Office of Scientific Research (AFOSR), the International Association of Hydraulic Engineering and Research (IAHR), QNET-CFD, and the National Institute of Aerospace (NIA).

There were 75 attendees at the workshop. Seven countries were represented, including the lnited States, France, Italy, Germany, Japan. United Kingdom, and Switzerland. Most of the workshop participants came from universities, but several companies and public sector research laboratories were represented as well.

The purpose of (FDVAL2004 was to bring together an international group of computational fluid dynamirs practitioners 10 assess the current capabilities of different classes of turbulent flow solution methodologies to predict flow fields induced by synthetic jets and separation control geonetries. The experimental data for the workshop were taken sperifically with (ED validation in mind. Therefore, a great deal of effort was expended to attempt to document most of the relevant boundary conditions. The 3-day workshop gave time for each participant to discuss their method and results. Each test case was concluded by a summary talk by the organizers, for which all of the contributed results were compiled. A panel discussion, whose focus was quality and trust for synthetic jet (FD and experiment, was also included in the workshop.

To encourage broad participation and to determine the general state-of-the-art, the decision was made early not to dictate particular boundary conditions. grids. or method of solution. For example. although the experimental velocity was given as a function of time near the centers of the jet exits for cases 1 and 2 . the participants were given the choice as to the precise boundary condition used to try to match it. While this strategy to broaden workshop participation was surcessful - solution methods ranged from reducedorder models through Reynolds-averaged Navier-Stokes (RANS), to large-eddy simulation (LES), and direct numerical simulation (DNS) - it also had an unavoidable downside. Differences in grids and boundary conditions represented an additional source of uncertainty when attempting to compare (FD results with each other.

The three test cases were chosen to represent different aspects of flow control physics. In test case 1 (synthetic jet into quiescent air). flow passed in and out of a slot $(1.27 \mathrm{~mm}$ wide by $35.56 \mathrm{~mm}$ long), which was located on the floor of an enclosed box $0.61 \mathrm{~m}$ per side. The jet was driven by a side-mounted circular piezo-electric diaphragm inside the cavity chamber beneath the floor. The frequency was approximately 445) $\mathrm{Hz}$, and the maximum velocity out of the slot was approximately $25-30 \mathrm{~m} / \mathrm{s}$. This case was considered to be nominally two-dimensional at the center plane of the slot. For case 1, the participants were asked to supply long-time-average jet width and velocity profiles at several locations. Also, phase-averaged velocities and turbulence quantities were requested at 8 different phases at several locations. Finally, time-history values of velocity at three points in the flow, as well as specific line contour plots of phase-averaged velocities were also requested.

In test case 2 (synthetic jet in a crossflow), flow passed in and out of a circular orifice $6.35 \mathrm{~mm}$ in diameter. The orifice was located on the floor of a wind tunnel splitter plate with a turbulent boundary layer at $\mathbf{M}=0.1$ and approximate boundary layer thickness of $21 \mathrm{~mm}$. The jet was driven elect ro-mechanically by a bottom-mounted square-shaped rigid piston mounted on an elastic membrane inside the cavity chamber 
beneath the splitter plate. The cavity was approximately $1.7 \mathrm{~mm}$ deep and the piston moved approximately $\pm 0.7 \mathrm{~mm}$. The frequenry was $150 \mathrm{~Hz}$, and the maximum velocity out of the orifice was approximately 1.32 . For case 2 . both long-time-average jet width and velocities as well as pliase-averaged velocities and turbulence quantities (9 phases) were requested at several locations. Furthermore, participants were asked to supply time-history values of velocity at three points in the flow, as well as specific line contour plots of both long-time-average and phase-averaged u-velority.

In test case 3 (flow over a hump nodel), turbulent flow at $\mathbf{M}=0.1$ passed over a hump of chord $420 \mathrm{~mm}$ mounted on the floor of a wind tumnel splitter plate. The hump used end-plates at both sides (the model had a span of $584.2 \mathrm{~mm}$ between the plates), and the flow was nominally two-dimensional at its center plane. The hump had a slot near $65 \%$ chord, near where separation naturally occurred. This case had two mandatory conditions: no-flow-control (no forced flow through the slot). and steady suction $(i m=0.01518$ $\mathrm{kg} / \mathrm{s}$ ). There was also one optional condition (the experiment was not completed in time for the workshop) of oscillatory (synthetic) jet control. In this case, the jet was driven electro-mechanically by a bottommounted rectangular-shaped rigid piston mounted on an elastic membrane deep inside the cavity chamber. The frequency was $138.5 \mathrm{~Hz}$, and the peak velocity out of the slot was approximately $27 \mathrm{~m} / \mathrm{s}$. For the case 3 no-flow-control and steady-suction conditions, participants were asked to supply $C^{\prime} p$ and $C_{f}$ along the hump surface, velocity and turbulence profiles at several locations, and streamine contour plots. For the optional synthetic jet condition, only long-time-average $C p$ along the hump surface was requested.

There was a great deal of CFD data submitted to this workshop. It is clearly not possible to show mosi of the results here. Suiminary plots as well as several spccific detaild plots are shown that we believe to be representative of the solutions as a whole. or which serve to illustrate specific points or differences. Additional detailed plots of the CFD results are available from the CFDVAL2004 website. ${ }^{14}$ It should also be noted that workshop participants were allowed to correct. resubnit, or withdraw their submissions during the month following the workshop; both this paper summary and the plots on the website contain updated information as of May 2004.

\section{Case 1: Synthetic Jet into Quiescent Air}

Tabulations of the submissions for ('ase 1 are given in Tables 1 and 2 . There were 8 contributors who ran 25 separate cases. There was one LES submission, one reduced-order model submission. one 2-D blended RANS-LES submission. and several laminar Navier-Stokes submissions (the 3-D laminar runs perhaps can also be characterized as under-resolved DNS); the others were unsteady RANS (IRANS). Most of the runs were computed in 2-D, but there were also a few 3-D computations. Note that none of the 3-D computations modeled the actual shape of the the cavity, including the circular diaphragm; instead, they were all computed using periodicity in the direction aligned with the slot s long axis. Six of the contributors modeled the cavity (or some approximation of the cavity) and two did not model any cavity. Of those who modeled the cavity, ONERA-flu3m and UKY-ghost applied a time-varying velocity on the side of the cavity where the diaphragm was located, derived from diaphragm-center displacement data. WASHU-wind and NASA-t Ins.3d also applied a similar boundary condition there. but based it on best matching of the data at the slot exit. (iWU-vicar3d used a different cavity shape with time-varying velocity boundary condition applied at the bottom wall. NCAT-quasid modeled the motion of the actuator with a quasi-1-D model.

All of the results were calculated with structured grids. Only two contributors (UKY-ghost and NASAthns.d) ran with the same grid, "2-D Structured Grid \#1". This grid. along with other structured and unstructured grids, were made available on the website several months prior to the workshop. Descriptions of these grids can be found at the website. ${ }^{14}$

In this section, we compare results for case 1 with particle image velocimetry (PIV) and hot wire data. It should be noted that other experimental data were later taken using a different piezo-electric diaphragm (these devices are prone to occasional failure). This later data also include laser doppler velorimetry (LDV) measurements in addition to PIV and hot wire, but they were also at slightly different conditions (higher maximum outflow velocity) than the data used for the workshop. The later data are not shown here, but 
are reported in Yao et al. ${ }^{15}$ A sketch showing the locations where most of the results from the computations were supplied is given in Fig. 1, and the definition of jet width used for this case is given in Fig. 2.

Time histories of v-velocities near the center of the slot exit are shown in Fig. 3. There is clearly a significant variation between the two measurement techniques (PIV and hotwire), so it is difficult to make a confident assessment of the (FD results. Both experimental measurements indicated approximately a $200^{\circ}$ phase difference between peak and trough, while many of the CFD methods yielded $180^{\circ}$. Some of the differences in particular phase-averaged results between ( FD and experiment could be a result of not matching the same phase.

Fig. 4 shows long-time-average v-velocity profiles along the centerline, $x=0$. Again, a significant difference can be seen between the two measurement techniques, especially very near the slot for $y$ less than approximately $2 \mathrm{~mm}$. There were also significant variations between the ('FD results. Most of them showed similar trends to the experiment, although NCAT-quasld and WARWICK-neat indicated a more rapid drop in velocity for $\mathrm{y}>10 \mathrm{~mm}$ compared to the other results.

Long-time-average results along two $y=$ constant lines $(y=0.1 \mathrm{~mm}$ and $\mathrm{y}=4 \mathrm{~mm}$, respectively) are shown in Figs. 5 and 6 . Just above the slot exit, at $y=0.1 \mathrm{~mm}$, all results except. POl'T-saturne greatly underpredicted the average jet magnitude. However, beginning near $1.2 \mathrm{~mm}$ and above, all the (CFD results agreed very well with the PIV experiment. An example of this better agreement is shown at $y=4 \mathrm{~mm}$ in Fig. 6. There was relatively little spread anong the ('FD results at this location. Although not shown. the variation between the ( $F D$ results increased at higher $y$-stations.

The long-time-average jet width is shown in Fig. 7 . Most CFD results tended to somewhat overpredict the width. The ONERA-flu3m laminar result was similar to the other methods near to the wall, but then predicted too much spreading of the jet past $y=4 \mathrm{~mm}$. It was more than twice as wide as the experimental results near $y=8 \mathrm{~mm}$. Although not shown, the (FD results had significantly greater variation for $y>8$ $11 \mathrm{~m}$.

For the sake of brevity, only one representative phase-averaged result is shown here. Fig. 8 shows vvelocity profiles at $y=4 \mathrm{~mm}$, at phase $=135^{\circ}$. Compared with the long-time-average results shown earlier, this typical phase-averaged result illustrates that there was a great deal more ( FD variation at this level of detail. Also, the comparison was not as good with experimental data.

Several participants investigated the effect of time step and grid size on the solution. Although not shown, time step had very little effect for any of the solutions. The effect of grid was relatively small near the wall, but it could be larger away from the wall. This is illustrated in Fig. 9, which shows long-timeaverage v-velocity along the centerline. IKY-ghost and POIT-saturne showed only minor variation, but the 3-D GWU-vicar3d results were affected by grid size and its spanwise extent. NASA-1.hns3d fine and medium grids gave nearly identical results, but the coarse grid was different.

The turbulence model's effect on the ('FD results was found to be fairly significant for this case. Results are shown in Fig. 10. For POIT-saturne, the $k-\varepsilon$ model compared better with experimental data than the Reynolds stress model (RSM) for this quantity. For WARWICK-neat, three different turbulence models were essentially the same for $\mathrm{y}<4 \mathrm{~mm}$, but then they behaved very differently beyond that. None of these agreed particularly well with experimental data. For WASHU-wind, Spalart-Allmaras (SA) and Menter's shear stress transport (SST) were fairly similar. especially for $\mathrm{y}<7 \mathrm{~mm}$, but the 2-D blended SST-LES method generally overpredicted the average velocity everywhere. For NASA-thns3d, SA and SST showed similar variation to that seen by WASHU-wind: the two models were close near the wall, then SST predicted somewhat larger velocities than SA further from the wall.

Although not shown, the computed turbulence quantities (e.g., $\left.u^{\prime} v^{\prime}\right)$ did not compare well at all with experimental data. and there was very large variation exhibited among (FD results. Also, there is some question whether the measured data is entirely a result of turbulence, or a result of unsteady "flapping" of the time-dependent jet. It was generally felt by the participants of the workshop that this case 1 flow is probably laminar in the beginning, then transitional further into the flow field. Therefore the use of a standard RANS turbulence model may not be entirely warranted.

As mentioned earlier, in spite of attempting to match the v-velocity phase at the slot outflow (see Fig. 3),

4 of :31

American Institute of Aeronautics and Astronautics Paper 2004-2217 
many of the participants had difficulty because the experimental variation was not sinusoidal ( $180^{\circ}$ peakto-peak). As a result, at rertain phases they found that the computed jet could be at a different position than in the experiment. This is illustrated by example flowfield contours at phase $=135^{\circ}$, shown in Fig. 11 . Similar to most other results (not shown). the NASA-thlns3d result at this phase had the extent of its peak jet velocity lower (near $4 \mathrm{~mm}$ ) than seen in the experimental dat a (near $7 \mathrm{~mm}$ ).

For this case, the 2-D laminar ONERA-flu3m result predicted too much jet spreading. However, the 2-D laminar NCAT-quas1d, 3-D laminar, and 3-D LES results were consistent with other (FFD methods in this regard. Different turbulence models could have significant effects, especially further into the flow field: the SA, SST, and POIT-saturne-ke models seemed to be of similar quality, and generally agreed best with the data among the URANS models. Surprisingly, there did not appear to be a distinct advantage to modeling the cavity for this case. as opposed to specifying a jet boundary condition at the surface. Regarding grid effect, 2-D grid levels of about 60.000 points (including cavity) were found to be sufficient to rapture the flow physics, whereas 16.000 points yielded noticeable differences in the solution. Anong 3-D results, changing from 460.000 to 700,000 points (or increasing the spanwise periodic extent) could significantly alter the solution far into the flow field. There was very little effect of changing time step, even with as low as $i \cdot 2$ steps per period.

\section{Case 2: Synthetic Jet in a Crossflow}

Tabulations of the submissions for Case 2 are given in Tables 3 and 4 . There were 5 contributors who ran 10 separate cases. There was one LES submission: the others used URANS. All runs were (necessarily) 3-D. All methods were second order in space and time. All submissions modeled the cavity, except for (IRA-zen which specified a time-varying profile at the orifice exit. However, both USTO-rans and NASA-fun3d altered the cavity shape. In the latter case, the bottom wall was made flat while keeping the volume the same as the original (stepped) geometry. Two of the contributors modeled the full plane, while the others modeled a half plane with symmetry imposed at the center plane. Each contributor used a different grid: four used structured grids and one used unstructured. The "Structured Grid \#1" and "Unstructured (irid \#1" were made available on the website several months prior to the workshop. Descriptions of these grids can be found at the website. ${ }^{14}$ The four contributors who modeled the cavity applied a time-dependent velocity specification at the cavity bottom wall: $\tilde{V}=V \cos (2 \pi f t)$. Each adjusted $V^{\prime}$ to achieve what was considered to be a reasonable match of the experimental $w$-velocity variation at the orifice exit.

In this paper, case 2 results are quantitatively compared only to LDV data. A sketch showing some of the LDV data measurement locations is given in Fig. 12. PIV data was also acquired at several planes. The reader interested in quantitatively comparing experimental results using the two different techniques is referred to Schaeffler and Jenkins. ${ }^{16}$

Time histories of velocities near the center of the orifice exit are shown in Fig. 13. The u-velocity component was captured well by three of the codes. CIRA-zen showed a higher value and NASA-fun3d showed a lower value than experimental results during the expulsion part of the cycle. All codes predicted a zero or near-zero cross-stream v-component of velocity, whereas the experimental data indicated a very large v-component during expulsion. The cause of this high experimental value is not known. Finally, all codes captured the w-velocity reasonably well (with some variation), although no one replicated the "dip" near phase $=160^{\circ}$. The cause for this dip in the experimental result is also not known. The cavity under the orifice was extremely shallow (nominally $1.7 \mathrm{~mm}$ deep neutral position with tunnel on), and the piston moved $\pm 0.77 \mathrm{~mm}$ up and down from this position. The volume in the cavity more than doubled from roughly 10,000 to 26,000 cubic $\mathrm{mm}$ during the cycle. It is questionable whether a simple non-moving-wall transpiration boundary condition, used by all of the CFD methods, is a very accurate model for this large a range of piston motion.

Fig. 14 shows long-time-average u-velocity profiles on the center plane at three downstream stations. Overall, there was fair agreement between CFD and experiment, but there was also a significant spread among the CFD results. Fig. 15 shows w-velocity profiles along one spanwise line and two streamwise lines. 
Along the spanwise line. there were no experimental LDV data, and there was a significant spread in the (FD results. Along the streamwise lines, the 5 (FD results again exhibited significant spread; two of the ( FD methods exhibited reasonably good agreement with experimental results along the $z=1011 m, y=0$ line (Fig. 15c).

Two of the participants examnined the effect of grid size on the solution. The results can be briefly summarized in a representative figure, Fig. 16. In general, the fine $(3.9$ million cells) and coarser $(0.49$ million cells) grids used in NASA-cf3d did not exhibit a dranatic infuence in the solution. However, for NASA-fun:3d the fine $(0.26$ million nodes) and coarser (46,000 nodes) grids did have a significant difference. For NASA-fun:3l, the finer grid produced a negative streanwise velocity during expulsion, but the coarser gricl dicl not.

Two of the participants investigated the effects of different turbulence models on the solution. Again, only one representative figure is shown here for the sake of brevity, Fig. 17. In NASA-cfl3d, three different models resulted in minor differences from each other, and none was clearly better in comparison with the experimental data. The two models used by USTO-rans also showed only minor differences from each other, and they were clearly different in character from both the NASA-cfl3d results and the experimental data. In other words, the turbulence models thenselves did not have as much of an impact as the combined effect of different codes, grids (in number of points and full plane vs. half plane), and other solution variations (such as alteration of the cavity shape by USTO-rans).

Only a few phase-averaged results are shown here. Fig. 18 shows u-velocity along a line 1D dowustreanu at three different phases. AII CFD results were in good agreement with each other and with experimental results at phase $=0^{\circ}$ (at this time the orifice is still in its suction phase, so there is little to no dynamic flow occurring ID downstream). However, at the two later phases the influence of the expulsion part of the cycle is felt at this location. The ('FD results captured the influence, generally following the trends seen in the experiment, but there was a significant spread in the solutions.

Phase-averaged turbulence quantities from the (FD solutions generally exhibited similar trends to each other, but again with a significant spread. There were usually larger discrepancies between CFD and experiment than the discrepancies seen between turbulence profiles. An example is shown in Fig. 19.

Finally, a sanple comparison between experiment and CFD over the entire plane ID downstream is shown in Fig. 20. This figure shows u-velocity contours at phase $=120^{\circ}$. It is intended as a qualitative comparison only. Also, only one (FD result is shown for brevity: other CFD results were qualitatively sinilar. Although details were different, this figure indicates that CFD predicted the overall structure of the dynamic flow resulting from the expulsion part of the cycle as it passes downst ream.

For this case study, LES vs. URANS did not appear to be a significant factor. In fact, overall (in a subjective sense) the two methods that tended to yield the most similar long-time-average and phaseaveraged mean-flow solutions were ONERA-flu3m (LES) and NASA-cfl3d (IRANS). In general, no one method, algorithm, or turbulence model stood out as being the best methodology for capturing the physics of this flow. Grid levels of about a half a million points or more appeared to be sufficient to capture the general character of the unsteady flow sufficiently well, whereas grids coarser than this could change the solution significantly. None of the participants submitted results examining the effect of time step; however, NASA-cflid performed computations that were not subnitted, varying between 720 and 1440 steps per cycle, and found very little effect.

\section{Case 3: Flow over a Hump Model (Separation Control)}

Tabulations of the submissions for (ase 3 are given in Tables 5 and 6 . There were 13 contributors who ran 56 separate cases. Methods were mostly RANS/IRANS, but there was also one DNS result and several blended RANS-LES results. Most of the runs were computed in 2-D, but there were also several 3-D computations. Some of the 3-D computations were periodic in the spanwise direction, and some were half-plane (either flat inviscid side wall or actual side plate geometry modeled viscously). Most of the contributors modeled the cavity, but several applied boundary conditions directly on the hump surface. 
Results were computed on both structured and unstructured grids. Nany contributors used the 2-D grids supplied on the website (for example. "2-D Structured (irid \#1“). Descriptions of these grids can be found there. ${ }^{14}$

Case 3 is different from cases 1 and 2 in that most of the results were not time-dependent. Only the optional oscillatory-control case was unsteady, and for that case only long-time-average (" $p$ 's were requested from the participants ( 8 of the contributors computed this. running $1 \%$ separate cases). However, when there is more extensive time-dependent data available in the future. the oscillatory-cont rol experiment may serve as a good test case for time-accurate validation exercises. A sketch showing the locations where most of the results from the computations were supplied is given in Fig. 21. (onputed pressures are compared with experimental data from surface-mounted pressure taps, and velocity and turbulence profiles are compared with PIV experimental data. Experimental details are reported in (ireenblatt et al. ${ }^{17}$

A summary of all of the C'FD results for the no-flow-control condition is shown in Fig. 22. (Note that separation and reattachment locations are not displayed in the figures for those methods that did not report skin friction.) As a whole. most (FD results missed the pressure levels over the hump between $0.2<\mathrm{x} / \mathrm{c}<0.6$. and also predicted higher pressures than experimental results in the separated region upstream of $x / c=1$. As will be shown below, the missed pressures were likely due to blockage effects caused by the side plates in the experiment. The separation location (not known precisely for the experiment) was predicted reasonably well by most ( $F D$ methods. and the reattachment location was predicted (for the most part) significantly downstream of the experimental location of $x / c=1.11$. Most models of similar type generally behaved similarly. Two exceptions were (IRA-zen-st-kprof-? which predicted separation later and reattachment earlier than other results with the SST model, and (IRA-zen-ke. which predicted reattachment further downstream than other results using a $k-\_$model. CIRA-zen also reported unusually low skin friction levels for all of its results.

A summary of all of the CFD results for the steady suction condition is shown in Fig. 23. Again, most CFD results overpredicted the pressure levels over the hump between $0.2<\mathrm{x} / \mathrm{c}<0.6$. Also, the pressures in the separated region did not exhibit the same levels or shape as experimental results. The separation location (again not known precisely for the experiment) was predicted to be slightly upstream of the experimental location, and the reattachment location was predicted to be significantly downstream of the experimental location of $\mathrm{x} / \mathrm{c}=0.94$ by all C $\mathrm{FD}$ methods. For the suction condition, there was generally a broader range exhibited in the results for a given turbulence model than for the no-flow-control condition. Notable results that showed the largest differences from other turbulence models of the same type were: CTR-fluent-sa-2. CTR-fluent-sa-1, NASA-rans-sst-weno5, and IS-fluent-ke.

The two figures, Figs. 22 and 23, are also instructive from the point of view of (FD uncertainty. The surface pressure coefficient plots illustrate the range of variation of (FD for these cases. This variation is caused by use of different grids, codes, turbulence models, and boundary conditions (including 2-D vs. 3-D modeling). In particular, it should be noted that the downstream boundary condition in internal flow cases such as this can affect the flow to some degree: by setting different back pressures, one can achieve different results. Individual differences in this boundary condition likely account for some of the CFD variation.

The tendency for most of the CFD results to miss the pressure levels over the front half of the hump was believed to be due to blockage effects in the experiment. Two pieces of evidence support this conject ure. First, the 3-D AZ-cobalt runs that accounted for the side plate physical shape (modeled as a viscous wall) resulted in improved levels there. Second, the 2-D NASA-cfi3d run that used an altered top wall shape to approximately account for the side-plate blockage (using area ratio of plate cross-section to tunnel cross section) resulted in excellent agreement of pressures over the front part of the hump compared with experimental data. These results are shown in Fig. 24. The grid used in the NASA-cfl3d case (2-D Structured \#.5) is described on the CFDVAL2004 website; this grid was created after the workshop. It should be noted from this figure that the 3-D AZ-cobalt runs also yielded good results in the separated region, whereas the 2-D NASA-cfl3d runs did not. This suggests that there may be 3-D separated structures along the back end of the side plates that further constrict the flow (additional blockage) in the separated region.

Although not shown, most of the contributed results were in fairly good agreement with experimental data 
(for both velority profiles and turbulent shear stress profiles) just upstream of the slot (especially for the noflow-control condition). And the velocity profiles inside the separated region were also predicted reasonably well, on the whole, for both no-flow-control and suction conditions. However, because the CFD results reattached too late, most velocity profiles compared poorly with experimental data at stations downstream of reattachment. The two exceptions to this were AZ-cobalt-des-1-3d and META-cfd++lns-3d for the noflow-control condition. Profiles using these methods (along with five other typical representative solutions) at $\mathrm{x} / \mathrm{c}=1.2$ are shown in Fig. 25. However, all results were poor downstream of reattachment for the suction condition. Fourteen representative results are shown at $\mathrm{x} / \mathrm{c}=1.0 \mathrm{in} \mathrm{Fig.} 26$.

A possible reason for reat arhment being predicted too late is that most of the current models and methods predicted turbulent shear stress to be too small in magnitude in the separated region. As an illustration of this tendency. Fig. 27 shows both u-velocity and turbulent shear stress for the suction condition at the location $\mathrm{x} / \mathrm{c}=0.8$, using several representative solutions. The velocity profiles exhibited a variation in shape, especially near the center of the profile, but the overall agreement with experimental results was fairly good for the RANS methods. However, the magnitude of the turbulent shear stress was seriously underpredicted. (The turbulent shear stress data had a maximum error of as much as $20 \%$, based on a pseudo-empirical uncertainty analysis. Nonetheless, the results still indicated a large difference between (FD and experiment.) One of the anomalies evident in the submissions was that the US-fluent results consistently yielded significantly larger-in-nagnitude turbulent shear stress levels, in better agreenent with experimental data, even though they used many of the same turbulence models as other codes. In any case, the US-fluent solutions still predicted reatiachment too far downstream, similar to the other submissions.

The DNS and blended RANS-LES solutions (DES. LNS, FSM) were generally on a par with the RANS methods; they, too, predicted reattachment too far downstream. However, DNS, LES, and 3-D blended RANS-LES models involve typirally finer grids than RANS methods, and require very lengthy run times. It is possible that future improvenents may result from additional efforts in these areas. As shown earlier in Fig. 25, a few of the blended RANS-LES models appeared to do a better job predicting velocity profiles near and downstream of reattachment than the RANS methods for the no-flow-control condition, but they did not improve results for the suction condition. Also, it is worth noting that AZ-cobalt-des predicted resolved turbulent shear stress levels dounstifam of reatiachment (for both no-flow-control and suction conditions) that were much higher in magnitude than most RANS results.

Many of the contributors investigated the effect of grid on the solution, for the no-flow-control and suction conditions. For 2-D, little influence was noted (all used a minimum of about 50,000 grid points). The influence of turbulence model has been shown earlier in Figs. 22 and 23. Generally, there were some differences between the models as expected. but all performed poorly when it came to predicting reattachment location. No one model stood out as performing consistently better for this case. A few contributors ran without modeling the cavity. In general this did not appear to either help or hurt, even for the suction case. CIRA-zen found that applying oblique suction improved results over applying normal suction.

A summary of all of the (FD results for the (optional) oscillatory control case is shown in Fig. 28. There was variation among the (:FD results, but in general they all exhibited similar trends. The results whose separated region pressure recovery occurred furthest upstream (in better agreement with experimental data) were IAZ-cflid, BOEING-overflow, and UMD-rans. NASA-fun2d investigated the effect of time step on this solution, and found very little effect.

\section{Summary and Conclusions}

Time-dependent flows involving unsteady flow control are difficult not only to compute with CFD, but also to measure experimentally. The (FDVAL2004 workshop in many ways ended up being as much of a workshop on experimental issues as on ( FD issues. From the two cases involving synthetic jets (case 1 and case 2), we learned that there are still some inconsistencies between different measurement techniques for certain aspects of these types of time-dependent flows. These differences were openly reported at the workshop, in order to foster honest and open dialog and to help encourage collaborative efforts to work

8 of 31 
toward improving future results. Most import antly. the workshop proved to be an ideal setting for providing a quality technical interchange between (FD and experimental scientists. where each rould learn about the capabilities and limitations inherent in the processes and tools of the other.

This paper forused on providing a summary of the ('FD results from the workshop. The workshop itself was designed to encourage wide participation and to establish a baseline for the state-of-the-art in the area of synthetic jet validation and turbulent separation control. Specific grids, boundary conditions, and methods of solution were not dictated to the participants. As a result. (FD variation was fairly large. However, trends could still be noted, including overall capabilities and shortromings. Many of the workshop participants suggested that, now that we have established a baseline for these cases. future CFD efforts should attempt to minimize known sources of CFD variation. especially regarding boundary conditions. It was also suggested that future experiments focus additional effort documenting the time-dependent boundary conditions, especially at and near the exit plane of the jet/suction slot or orifice.

The bottom line from the (.FD results can be summed up as follows: no one C.FD technique excelled above others, and there was wide variation (especially for time-dependent results), and only qualitative agreement with experimental data. In other words, the "state-of-the-art" CFD methods of today are not fully adequate to consistently and accurately predict these types of flows. What is today"s "state-of-the-art"? Most of the contributors used IRANS for the time-dependent cases and RANS to compute the steady cases. A wide variety of turbulence models were employed. Most ( FD methods were second order in space and time. Some contributors used higher order, but there did not appear to be any obrious benefits from doing so for these cases. Most contributors utilized transpiration boundary conditions on a fixed grid to simulate moving walls. The few blended RANS-LES. LES, and DNS solutions showed merit, and were of similar quality to the RANS and URANS solutions. We believe that with todays increased computer power and improved algorithms, these advanced methods are currently coming of age and represent the way much of C.FD will be performed in the future. However, as yet they showed no clear benefits over RANS/URANS in the sense of providing consistently better results for the workshop cases.

Case 1 (synthetic jet into quiescent air) was a difficult experiment to simulate. The flow field was probably mostly laminar or transitional, so it was unclear how best to simulate it. The piezo-elertric driver used in the experiment was difficult to model using (FD because it moved like a drum (and possibly with multiple shape modes), and not like a rigid piston. The experiment indicated a deviation from periodicity in the velocity near the jet exit that was not completely simulated or captured by the CFD results, and caused specific phase results to be mis-aligned. For example, at phase $=13.5^{\circ}$ in the experiment, the jet extended higher into the field than at the same phase as defined by most of the CFD runs. Long-time-average results showed deviations from experimental data very near to the slot as well as far from the slot. In the intermediate range (4-8 $\mathrm{mm}$ from the slot), the results were generally better. CFD vielded significantly larger variations in the phase-averaged quantities. Except for a few cases, average jet width was usually somewhat overpredicted by CFD in the near field. In the IRANS simulations, turbulence models were found to have a significant effect for this case. In general, the $k-\equiv, S A$, and SST models performed better compared to experimental data than other models tested.

Case 2 (synthetic jet in a crossflow) was the least computed of the three cases, probably owing to its being both time-dependent and (necessarily) 3-D. Similar to case 1, the time-dependent experimental velocities measured near the orifice exit exhibited anomalies not captured or modeled by C.FD. In particular, the experiment exhibited a dip in w-velocity on the downstroke and a very large spanwise velocity component during the expulsion part of the cycle that none of the CFD methods accounted for. In spite of this. reasonably good qualitative results were obtained compared to experimental results, but there were significant CFD variations in both the long-time-average and the pllase-averaged results. No one method, algorithm, or turbulence model stood out as being the best methodology. Even LES vs. URANS did not appear to be a significant factor. Cienerally different turbulence models for IRANS did not have as much of an impact on this case as different grids, codes, and other solution variations.

Case 3 (flow over a hump model) had the greatest number of workshop participants, since the required cases were nominally steady and 2-D. However, it was discovered after the workshop that the side plates used 
in the tumnel cansed blockage that, if not modeled, resulted in relatively minor (but noticeable) overpredietion of the pressures over most of the hump. Also, based on some :3-D results that modeled the side plates viscously and obtained good pressure comparisons in the separated region, it is likely that flow structures near the back of the plates constrict the flow even further in that region. In other words, in spite of this flow appearing to be relatively simple, computing the wall pressures accurately can require full 3 -D modeling or else some sort of blockage corrections. Overall, case 3 was not a severe test from the point of view of predicting separation. But ('FD results were deficient in another important regard: they consistently predicted the reattachment location to be significantly further downstream than the location documented in the experiment. This same behavior occurred regardless of turbulence model or method; even a IDNS computation predicted too long of a separation bubble. Inside the bubble itself, most computations predicted velocity profiles in reasonably good agreement with experimental data, but turbulent shear stresses were underpredicted in magnitude. This underprediction is consistent with delayed reattachment, because it indicates redured turbulent mixing inside the separated region compared with experimental data.

In conclusion, the ('FDVAL2004 workshop has established a benchmark for three different flows involving syuthetic jets and turbulent separation control. Although the current state-of-the-art CFD methods are deficient in being able to consistently and accurately predict these flows, two areas have been identified as key to improvement.

- First, for synthetic jets, it is important to employ consistent boundary conditions when multiple ( $F D$ methods are compared. Only then will we be able to isolate and work to correct deficiencies in the ('FD models and methods. Implicit in this need is the requirement that rxperiments be used to document extremely detailed and arcurate time-dependent flow field variables at and near the slot/orifice exits.

- Second, for the hump model case, turbulence models (for RANS) or other methods such as LES or blended RANS-LES need to be improved/developed/ralibrated to increase the mixing in the separated region and bring about earlier reattachment and flow recovery.

\section{Acknowledgments}

The authors would like to thank H. Atkins, P. Balakumar, and M. Carpenter of NASA Langley for their valuable contributions and useful discussions during the planning and execution of the CFDVAL2004 workshop. Also. J. Sawyer and P. Greene of NASA Langley are acknowledged for their help and expertise in arranging and rarrying out many particulars involved in the organization of the workshop.

\section{References}

${ }^{1}$ Lachmann, G. V.. "Boundary Layer and Flow Control. Its Principles and Application." Volume 1, Pergamon Press. New York, 1961.

'Seifert. A., Darabi, A., and Wygnanski, I., "Delay of Airfoil Stall by Periodic Excitation," Journal of Aircraft. Vol. 33. No. 4, 1996, pp. 691-698.

"Smith, B. L. and Glezer. A.. "The Formation and Evolution of Synthetic Jets," Physics of Fluits, Vol. 10, No. 9.1998. pp. $2281-2297$.

${ }^{4}$ Amitay, M.. Smith. D. R., Kibens. V., Parekh. D. E., and Glezer, A., “Aerodynamic Flow Control over an Unconventional Airfoil Using Synthetic Jet Actuators." AIAA Journal, Vol. 39, No. 3, 201, pp. 361-370.

${ }_{5}^{5}$ Peterson, S. D. and Plesniak, M. W.. "Evolution of Jets Emanating from Short Holes into Crossflow," Journal of Fluid Mechanics, Vol. 50:3, 2004, pp. 57-91.

${ }^{6}$ Milanovic. I. M. and Zaman. K. B. M. Q., "Fluid Dynamics of Highly Pitched and Yawed Jets in Crossfow." AIAA Journal, Vol. 42. No. 5. 2004. pp. 874-882.

"Greenblatt. D., Wygnanski. I. J., "The Control of Flow Separation by Periodic Exritation." Progress in Atrosfiact Sciences. Vol. 36, 2000, pp. 487-545.

${ }^{8}$ Yuan, L. L., Street, R. L., and Ferziger, J. H., "Large-Eddy Simulations of a Round Jet in Crossflow," J. Fluid Mech., Vol. 379, 1999, pp. 71-104. 
${ }^{9}$ Huang. L.. Huang. (i.. LeBrau. K., Hauser. Th., "Optimization of Blowing and Suction on NAC'A O012 Airfoil lising Genetic Algorithm." AIA Paper 2004-0225. January 2004.

${ }^{10}$ Ravi. B. R.. Mittal. R., and Najjar, F. M.. "Study of Three-Dimensional Synthet ic Jet Flowfields using Direct Numerical Simulation." AlAA Paper 2004-0091. January 2004.

"Yamaleev, N. K. and Carpenter. M. H., "A Rerlured-Order Model for Efficient Simulation of Synthetir Jet Actuators." NASA/TM1-2003-212664. December 2003.

12 Viken, S. A.. Vatsa. V. N.. and Rumsey. C. L., "Flow Control Analysis of the Hump Model with RANS Tools," AIAA Paper 2003-0218. January 2003.

1. Agarwal, R.. Vardillo. J.. Tan. Y.. ('ui. J., Guo, D.. Jain, H.. Cary, A., and Bower. W.. "Flow Control with Synthetic and Pulsed Jets: Applications to Virtual Aesushaping. Thrust-Vectoring. and Control of Separation and Cavity Osrillations." AIA A Paper 2004-0746, January 2004.

14 Sellers, W. L. and Rumsey, C. L.. http://cfdval2004larc.nasa.gov. 2004.

1 Yao, C. S., Chen, F. J., Neuhart. D., and Harris, J., "Synthetic Jet Flow Field Database for CFD Validation," AIAA Paper 2004-2218. Jume-July 2004.

16. Schaeffler. N. W. and Jenkins. L. N.. "The Isolated Synthetir Jet in Crossfow: A Benchrnark for Flow Cont rol Simulation." AIAA Paper 2004-2219. June-July 2004.

ii Greenhlatt. D. Paschal. K. B.. Schaeffler. N. W., Washburn, A. E.. Harris. J., and Yao. C. S.. "A Separation C'ontrol CFD Validation Test Case. Part 1: Baseline and Steady Suction." AIAA Paper 2004-2220, June-July 2004. 
Table 1. Case 1 Summary of Submissions

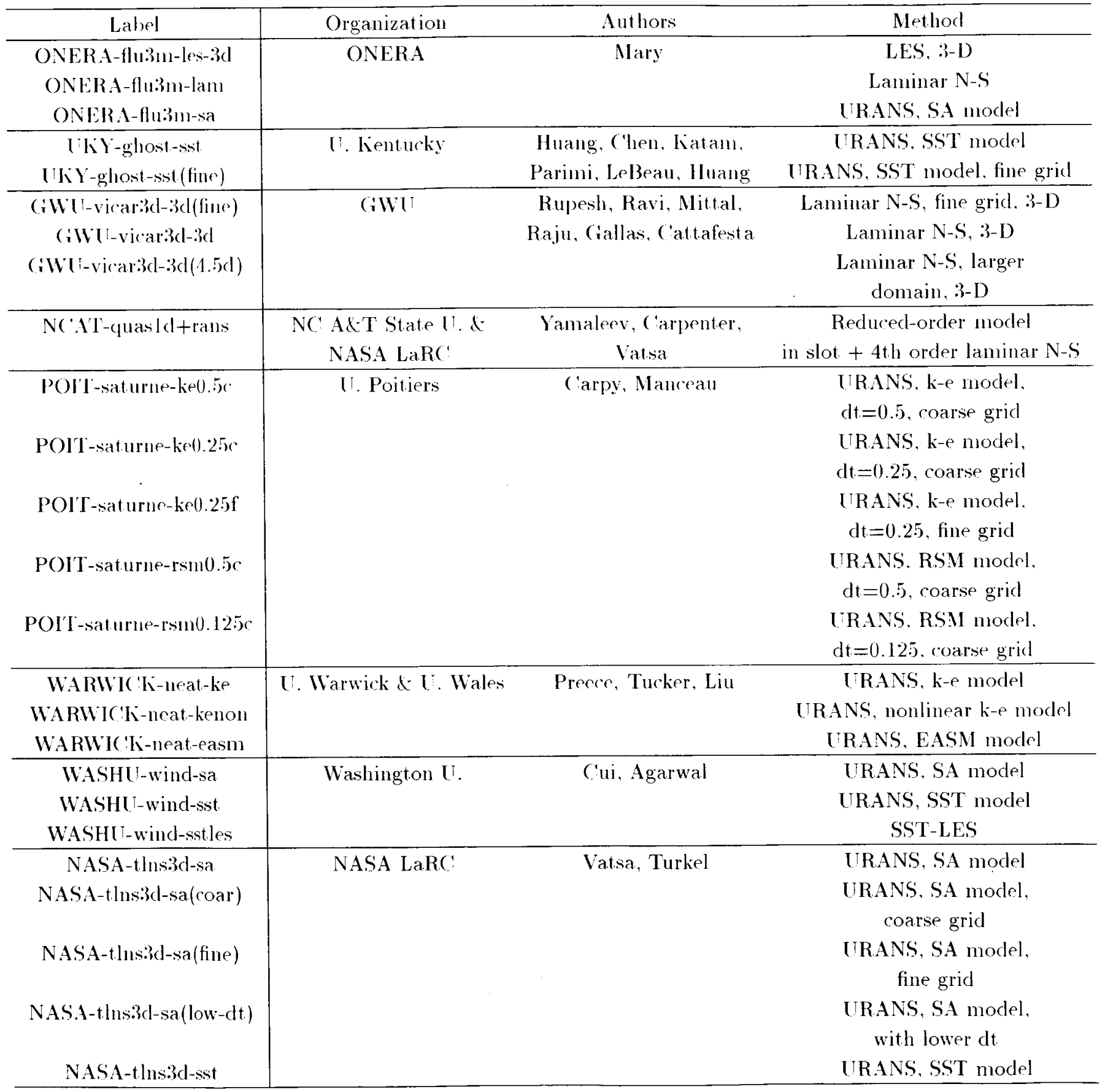


Table 2. Case 1 Summary of Grids and Time Steps

\begin{tabular}{|c|c|c|c|}
\hline Label & Grid type & Grid size & Time steps / cycle \\
\hline ONERA-flu3m-3d-les & 3-D Structured, periodic & 980,000 cells & 5000 \\
\hline ONERA-flu3m-lam & 2-D Structured & 51,700 cells & 5000 \\
\hline ONERA-flu3m-sa & 2-D Structured & 51,700 cells & 5000 \\
\hline UKY-ghost-sst & 2-D Structured Grid\#1 & 63.553 points & 2880 \\
\hline UKY-ghost-sst(fine) & 2-D Structured Grid\#2 & 198,545 points & 2880 \\
\hline (iWU-vicar3d-3d(fine) & 3-D Structured, periodic & 696.960 points & 14,000 \\
\hline GWI-vicar3d-3d & ?D Structured, periodic & 464,640 points & 14,000 \\
\hline GWU-vicar3d-3d(4.5d) & 3-D Structured, periodic & 696.960 points & 14.000 \\
\hline NCAT-quas $1 \mathrm{~d}+$ rans & 2-D Structured & 98.379 points & 118,567 \\
\hline POIT-saturne-ke0.5c & 2-D Structured (no cavity) & 15,707 cells & 720 \\
\hline POIT-saturne-ke $0.25 \mathrm{c}$ & 2-D Structured (no cavity) & 15,707 cells & 1440 \\
\hline POIT-saturne-ke0.25f & 2-D Structured (no cavity) & 62,828 cells & 1440 \\
\hline POIT-saturne-rsm0.5c & 2-D Structured (no cavity) & 15,707 cells & 720 \\
\hline POIT-saturne-rsm0.125c & 2-D Structured (no cavity) & $15.70 \bar{c}$ cells & 2880 \\
\hline WARWICK-neat-ke & 2-D Structured (no cavity) & 4851 points & 8600 \\
\hline WARWICK-neat-kenon & 2-D Structured (no cavity) & 4851 points & 3600 \\
\hline WARWICK-neat-easm & 2-D Structured (no cavity) & 4851 points & 3600 \\
\hline WASHU-wind-sa & 2-D Structured & 35,986 points & 10.000 \\
\hline WASHU-wind-sst & 2-D Structured & 35.986 points & 10.000 \\
\hline WASHU-wind-sstles & 2-D Structured & 35.986 points & 10,000 \\
\hline NASA-thns $3 d-s a$ & 2-D Structured Grid\#1 & 63,553 points & 72 \\
\hline NASA-tIns3d-sa(coar) & 2-D Structured & 16,107 points & 72 \\
\hline NASA-tlns3d-sa(fine) & 2-D Structured & 87,753 points & 72 \\
\hline NASA-tlns $3 d-s a(l o w-d t)$ & 2-D Structured Grid\#1 & 6.3.5.5.3 points & 144 \\
\hline NASA-tlns:3d-sst & 2-D Structured Grid\#1 & 63,553 points & 72 \\
\hline
\end{tabular}


Table 3. Case 2 Summary of Submissions

\begin{tabular}{c|ccc}
\hline Label & Organization & Authors & Method \\
\hline NASA-cfl3d-sa & NASA LaRC & Rumsey & URANS, SA model \\
NASA-cfl3d-sa(fine) & & & URANS, SA model, fine grid \\
NASA-cflid-sst & & URANS, SST model \\
NASA-cfl3d-easmlio & & & URANS, EASM-ko model \\
\hline ISTO-rans-tlv & USTO \& ETH & Azzi, Lakehal & URANS, 2-layer k-e TLV model \\
USTO-rans-easm & & URANS, EASM model \\
\hline ONERA-flu3m-les & ONERA & Dandois, Garnier, Sagaut & LES \\
\hline (IRA-zen-ke-nocav & CIRA & Marongiu & URANS, k-e model \\
\hline NASA-fun3d-sa & NASA LaRC & Atkins & URANS, SA model \\
NASA-fun3d-sa(fine) & & & URANS, SA model, fine grid \\
\hline
\end{tabular}

Table 4. Case 2 Summary of Grids and Time Steps

\begin{tabular}{|c|c|c|c|}
\hline Label & Grid type & Grid size & Time steps / cycle \\
\hline NASA-cfl3d-sa & $\begin{array}{c}\text { Full-plane, every other } \\
\text { point of Structured Cirid\#1 }\end{array}$ & 0.49 million cells & 720 \\
\hline NASA-cfl3d-sa(fine) & $\begin{array}{c}\text { Full-plane, Structured } \\
\text { Grid\#1 }\end{array}$ & 3.9 million cells & 720 \\
\hline NASA-cfl3d-sst & $\begin{array}{l}\text { Full-plane, every other } \\
\text { point of Structured Grid\#1 }\end{array}$ & 0.49 million cells & 1440 \\
\hline NASA-cfl3d-easmko. & $\begin{array}{l}\text { Full-plane, every other } \\
\text { point of Structured Grid\#1 }\end{array}$ & 0.49 million cells & 1440 \\
\hline USTO-rans-tlv & Half plane structured & 0.21 million cells & 360 \\
\hline USTO-rans-easm & Half plane structured & 0.21 million cells & 360 \\
\hline ONERA-flu3m-les & Full plane structured & 1.7 million cells & 6667 \\
\hline CIRA-zen-ke-nocav & $\begin{array}{l}\text { Half plane structured } \\
\text { (no cavity) }\end{array}$ & 775,680 cells & 720 \\
\hline NASA-fun3d-sa & Half plane unstructured & 46,000 nodes & 720 \\
\hline NASA-fun3d-sa(fine) & $\begin{array}{l}\text { Half plane Unstructured } \\
\text { Grid\#1 }\end{array}$ & 0.26 million nodes & 720 \\
\hline
\end{tabular}


Table 5. Case 3 Summary of Submissions

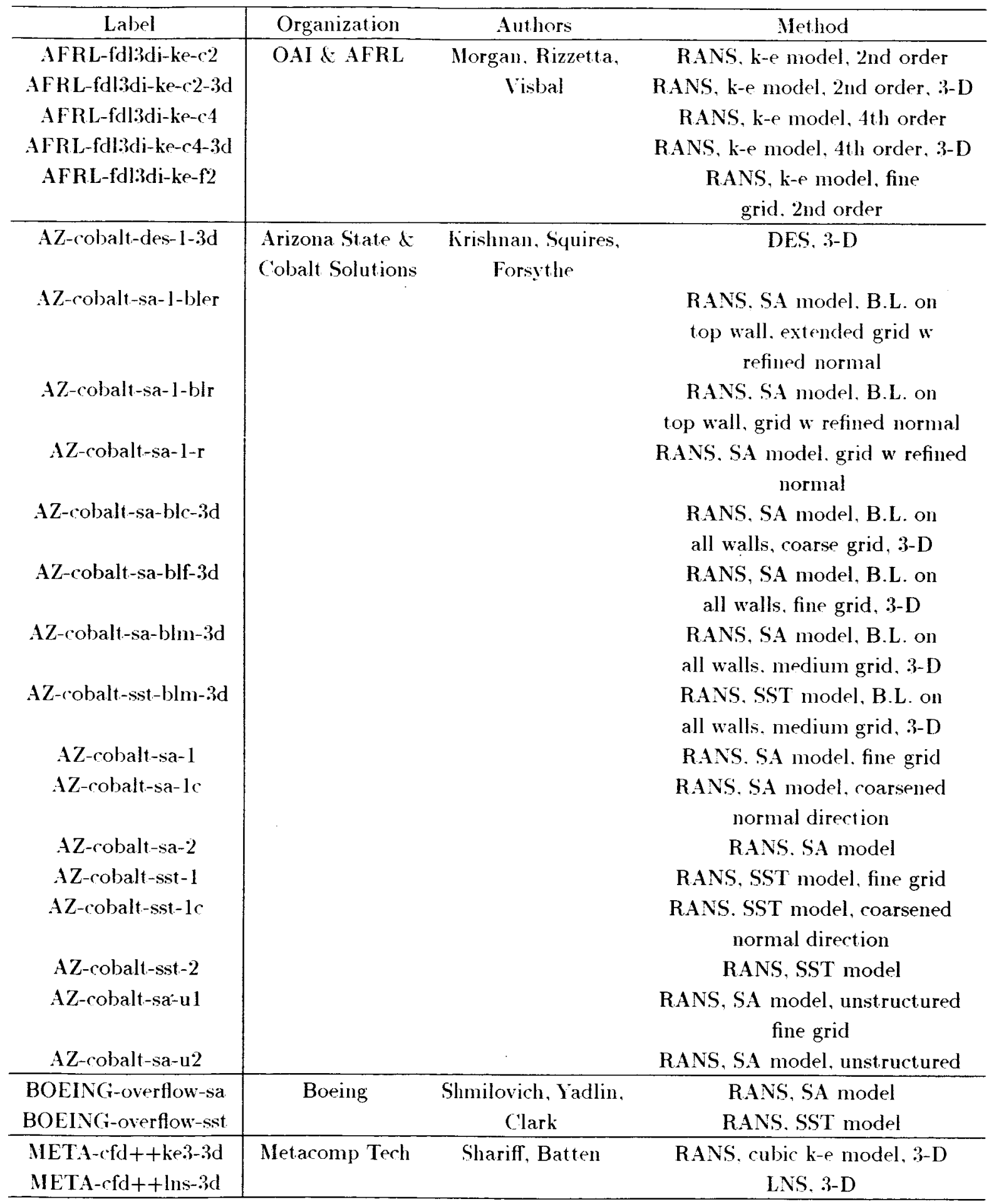

15 of 31 
Table 5. Case 3 Summary of Submissions, cont ${ }^{\circ} d$

\begin{tabular}{|c|c|c|c|}
\hline Label & Organization & Authors & Method \\
\hline ('TR-fluent-sa-1 & \multirow[t]{12}{*}{ CIRA \& CTR } & \multirow{12}{*}{$\begin{array}{l}\text { Marongiu, laccarino, } \\
\text { Catalano, Amato }\end{array}$} & RANS, SA model, fine grid \\
\hline ( TR-fluent-sa-2 & & & RANS. SA model \\
\hline (IRA-zenl-sst-kprof-3 & & & RANS, SST model with \\
\hline & & & k-profile at inflow \\
\hline ( 'IRA-zen-sst-11j-3) & & & RANS, SST model. \\
\hline & & & normal-jet suction \\
\hline \multirow[t]{2}{*}{ (IRA-Zen-sst-oj-3) } & & & RANS, SST model. \\
\hline & & & oblique-jet suction \\
\hline ('IRA-ZCH1-sst-3) & & & RANS, SST model \\
\hline ('IRA-zen-ke-3) & & & RANS, k-e model \\
\hline ('IRA-zen-ke & & & RANS, k-e model, fine grid \\
\hline (IRA-zenl-sst & & & RANS. SST model, fine grid \\
\hline NASA-cflBd-easm-2 & \multirow[t]{6}{*}{ NASA LaRC } & \multirow[t]{6}{*}{ Rumsey } & RANS. EASM model \\
\hline NASA-rfl:3d-sa-1 & & & RANS SA model, fine grid \\
\hline NASA-cflid-sa-2 & & & RANS, SA model \\
\hline NASA-cflid-sst-2 & & & RANS, SST model \\
\hline NASA-cflid-sa-top-5 & & & RANS, SA nodel, top wall \\
\hline & & & modified for blockage \\
\hline \multirow[t]{2}{*}{ NASA-rans-sst-weno5 } & \multirow[t]{2}{*}{ NASA LaRC } & \multirow[t]{2}{*}{ Balakumar } & RANS, SST model, \\
\hline & & & 5 th order weno \\
\hline \multirow{2}{*}{$\begin{array}{l}\text { NASA-fun2d-sa-u1 } \\
\text { NASA-fun2d-sa-u2 }\end{array}$} & \multirow[t]{2}{*}{ NASA LaRC: } & \multirow[t]{2}{*}{ Viken } & RANS, SA model, fine grid \\
\hline & & & RANS, SA model \\
\hline IAZ-cflisd-easmfsm-3d & U. Arizona & Israel, Fascl & FSM with linear EASM, 3-D \\
\hline [AZ-dns-3d & I. Arizona & Postl. Wernz, Fasel & DNS. :B-D \\
\hline IT-ghost-sist-1 & \multirow[t]{2}{*}{ I. Kentucky } & \multirow[t]{2}{*}{$\begin{array}{l}\text { Katam, Chen, Huang, } \\
\text { Parimi. LeBeau, Huang }\end{array}$} & $\begin{array}{l}\text { RANS, SST model, } \\
\text { fine grid }\end{array}$ \\
\hline UK-ghost-sst-2 & & & RANS, SST model \\
\hline \multirow{4}{*}{$\begin{array}{l}\text { UMD-rans-sa-cent-2 } \\
\text { UMD-rans-sa-cent-2-3d } \\
\text { UMD-rans-sst-cent-2 } \\
\text { UMD-rans-sa-cent-1 }\end{array}$} & \multirow[t]{6}{*}{ U. Maryland } & \multirow[t]{6}{*}{ Duraisamy, Baeder } & RANS (central), SA model \\
\hline & & & RANS (central), SA model, 3-D \\
\hline & & & RANS (central), SST model \\
\hline & & & $\begin{array}{l}\text { RANS (central), SA model, } \\
\text { fine grid }\end{array}$ \\
\hline IMD-rans-sa-roe-2 & & & RANS (Roe), SA model \\
\hline IMD-rans-sst-roe-2 & & & RANS (Roe), SST model \\
\hline US-fluent-ko & \multirow[t]{5}{*}{ Utah State } & \multirow[t]{5}{*}{ Spall, Phillips, Alley } & RANS, $k$-o model \\
\hline US-fluent-ke & & & RANS, k-e model \\
\hline US-fluent-sa & & & RANS, SA model \\
\hline US-fluent-sst & & & RANS, SST model \\
\hline ISS-fluent-vef & & & RANS, v2f model \\
\hline
\end{tabular}


Table 6. Case 3 Summary of Grids and Time Steps

\begin{tabular}{|c|c|c|c|}
\hline Label & (irid type & Grid size & Time steps / cycle \\
\hline AFRL-fdl:3di-ke-c2 & 2-D Structured & 50.410 points & 5.948 \\
\hline AFRL-fdl:3di-ke-c $2-3 d$ & $\begin{array}{l}\text { 3-D Structured } \\
\text { (half span / inviscid side) }\end{array}$ & 2.6 million points & $\mathrm{N} / \mathrm{A}$ \\
\hline AFRL-fdl:3di-ke-c4 & 2-D Structured & 50.410 points & 11.896 \\
\hline AFRL-fdl3di-ke-c4-:3d & $\begin{array}{c}\text { 3-D Structured } \\
\text { (half span / inviscid side) }\end{array}$ & 2.6 million points & $N / A$ \\
\hline AFRL-fdl:3di-ke-f2 & 2-D Structured & 199,790 points & 11.896 \\
\hline$A Z$-cobalt-des-1-3d & $\begin{array}{l}\text { 3-D Structured } \\
\text { (periodic span) }\end{array}$ & $\begin{array}{l}4.7 \text { million nodes / } \\
4.5 \text { million cells }\end{array}$ & $\mathrm{N} / \mathrm{A}$ \\
\hline AZ-cobalt-sa-1-bler & $\begin{array}{l}\text { 2-D Structured (extended } \\
\text { upstream, refined } \\
\text { normal dir) }\end{array}$ & 254.208 cells & $\mathrm{N} / \mathrm{A}$ \\
\hline AZ-cobalt-sa-1-blr & $\begin{array}{l}\text { 2-D Structured (refined } \\
\text { normal dir) }\end{array}$ & 241,920 cells & $\mathrm{N} / \mathrm{A}$ \\
\hline AZ-cobalt-sa-1-r & $\begin{array}{c}\text { 2-D Structured (refined } \\
\text { normal dir) }\end{array}$ & 241.920 cells & $\mathrm{N} / \mathrm{A}$ \\
\hline AZ-cobalt-sa-blc-3d & $\begin{array}{l}\text { 3-D Unstructured } \\
\text { (half span w plate) }\end{array}$ & $\begin{array}{l}610,881 \text { nodes / } \\
2.6 \text { million cells }\end{array}$ & $\mathrm{N} / \mathrm{A}$ \\
\hline AZ-cobalt-sa-blf-3d & $\begin{array}{l}\text { 3-D Unstructured } \\
\text { (half span w plate) }\end{array}$ & $\begin{array}{l}2.3 \text { million nodes / } \\
10.7 \text { million cells }\end{array}$ & $\mathrm{N} / \mathrm{A}$ \\
\hline AZ-cobalt-sa-blm-3d & $\begin{array}{l}\text { 3-D Instructured } \\
\text { (half span w plate) }\end{array}$ & $\begin{array}{l}1.1 \text { million nodes / } \\
4.9 \text { million cells }\end{array}$ & $\mathrm{N} / \mathrm{A}$ \\
\hline AZ-cobalt-sst-blm-3d & $\begin{array}{l}\text { 3-D Instructured } \\
\text { (half span w plate) }\end{array}$ & $\begin{array}{l}1.1 \text { million nodes / } \\
4.9 \text { million cells }\end{array}$ & $\mathrm{N} / \mathrm{A}$ \\
\hline AZ-cobalt-sa-1 & 2-D Structured Girid\#1 & 208.320 cells & $\mathrm{N} / \mathrm{A}$ \\
\hline AZ-cobalt-sa-1c & 2-D Structured & 110,880 cells & 722 \\
\hline AZ-cobalt-sa-2 & 2-D Structured (irid\#2 & 52,080 cells & $\mathrm{N} / \mathrm{A}$ \\
\hline AZ-cobalt-sst-1 & 2-D Structured (irid\#1 & 208.320 cells & $\mathrm{N} / \mathrm{A}$ \\
\hline AZ-cobalt-sst-1c & 2-D Structured & 110,880 cells & $\mathrm{N} / \mathrm{A}$ \\
\hline AZ-cobalt-sst-2 & 2-D Structured Grid\#2 & 52,080 cells & $\mathrm{N} / \mathrm{A}$ \\
\hline AZ-cobalt-sa-u1 & $\begin{array}{c}\text { 2-D Unstructured } \\
\text { Grid\#1 }\end{array}$ & $\begin{array}{l}123,703 \text { nodes / } \\
24 \bar{\tau}, 404 \text { cells }\end{array}$ & $N / A$ \\
\hline AZ-cobalt-sa-u2 & $\begin{array}{c}\text { 2-D Unstructured } \\
\text { Grid\#2 }\end{array}$ & $\begin{array}{c}57.152 \text { nodes / } \\
114.302 \text { cells } \\
\end{array}$ & N/A \\
\hline BOEING-overflow-sa & 2-D Structured overset & 47,790 points & 800 \\
\hline BOEING i-overflow-sst & 2-D Structured overset & 47,790 points & $\mathrm{N} / \mathrm{A}$ \\
\hline META-cfd ++ ke $3-3 \mathrm{~d}$ & $\begin{array}{l}\text { 3-D Structured } \\
\text { (half span) }\end{array}$ & 2.472 .520 cells & $\mathrm{N} / \mathrm{A}$ \\
\hline META-cfd++lns-3d & $\begin{array}{l}\text { 3-D Structured } \\
\text { (periodic span) }\end{array}$ & $1,816,000$ cells & $\mathrm{N} / \mathrm{A}$ \\
\hline
\end{tabular}


Table 6. Case 3 Summary of Grids and Time Steps (cont ${ }^{\circ}$ )

\begin{tabular}{|c|c|c|c|}
\hline Label & Grid type & Grid size & Time steps / cycle \\
\hline (TR-fluent-sa-1 & $\begin{array}{c}\text { 2-D Structured Grid\#1 } \\
\text { w/o zone } 4\end{array}$ & 197,952 ceells & $\mathrm{N} / \mathrm{A}$ \\
\hline (TR-fluent-sa-2 & $\begin{array}{c}\text { 2-D Sitructured Grid\#2 } \\
\text { w/o zone } 4\end{array}$ & 49,488 cells & $\mathrm{N} / \mathrm{A}$ \\
\hline ('IRA-zen-sst-kprof-3 & $\begin{array}{l}\text { 2-D Structured (irid\#: } \\
\text { (no (avity) }\end{array}$ & $14:, 61: 3$ points & $N / A$ \\
\hline (JRA-zen-sst-nj-3 & $\begin{array}{c}\text { 2-D Structured (irid\#: } \\
\text { (no cavity) }\end{array}$ & 143.613 points & $\mathrm{N} / \mathrm{A}$ \\
\hline (IRA-zen-sst-oj-3 & $\begin{array}{c}\text { 2-D Structured Giril\#:3 } \\
\text { (no cavity) }\end{array}$ & 143.613 points & $N / A$ \\
\hline (IRA-zent-sst-3) & $\begin{array}{c}\text { 2-D Structured Girid\#:3 } \\
\text { (no cavity) }\end{array}$ & 143,613 points & $N / A$ \\
\hline ('IRA-zen-ke-3) & $\begin{array}{c}\text { 2-D Structured Grid\#:3 } \\
\text { (no cavity) }\end{array}$ & 143.613 points & 720 \\
\hline CIRA-zen-ke & $\begin{array}{l}\text { 2-D Structured grid } \\
\text { (no (avity) }\end{array}$ & 171.072 cells & $\mathrm{N} / \mathrm{A}$ \\
\hline CIRA-zen-sst & $\begin{array}{l}\text { 2-D Structured grid } \\
\text { (no cavity) }\end{array}$ & 171,072 cells & $N / A$ \\
\hline NASA-cfl3d-easm-2 & 2-D Structured Grid\#2 & 52.080 cells & $N / A$ \\
\hline NASA-cflidl-sa-1 & 2-D Structured Grid\#1 & 208.320 cells & 360 \\
\hline NASA-cflid-sa-2 & 2-D Structured (irid\#2 & $52,0 \times 0$ cells & $N / A$ \\
\hline NASA-ct3d-sst-2 & 2-D Structured Grid\#2 & 52,080 cells & $N / A$ \\
\hline NASA-cfl3d-sa-top-5 & 2-D Structured Grid\#5) & 52.080 cells & $\mathrm{N} / \mathrm{A}$ \\
\hline NASA-rans-sst-weno 5 & $\begin{array}{c}\text { 2-D Structured overset } \\
\text { (no cavity) }\end{array}$ & 103,452 points & $\mathrm{N} / \mathrm{A}$ \\
\hline NASA-fun2d-sa-u1 & $\begin{array}{c}\text { 2-D Unstructured } \\
\text { Grid\#1 }\end{array}$ & $\begin{array}{c}123,703 \text { nodes / } \\
247.404 \text { cells }\end{array}$ & $200 \& 400$ \\
\hline NASA-fun2d-sa-u2 & $\begin{array}{l}\text { 2-D Unstructured } \\
\text { Grid\#2 }\end{array}$ & $\begin{array}{c}57,152 \text { nodes / } \\
114,302 \text { cells } \\
\end{array}$ & $\mathrm{N} / \mathrm{A}$ \\
\hline UAZ-cfl3d-easmfsm-3d & $\begin{array}{c}\text { 3-D Structured } \\
\text { (periodic span, no cavity) }\end{array}$ & 2.8 million points & 200 \\
\hline UAZ-dns-3d & $\begin{array}{c}\text { 3-D Structured } \\
\text { (periodic span, no cavity) }\end{array}$ & 105.2 million points & $\mathrm{N} / \mathrm{A}$ \\
\hline UK-ghost-sst-1 & $\begin{array}{c}\text { 2-D Structured Grid\#1 } \\
\text { w/o zone } 4\end{array}$ & 197,952 cells & $\mathrm{N} / \mathrm{A}$ \\
\hline UK-ghost-sst-2 & $\begin{array}{c}\text { 2-D Structured Grid\#2 } \\
\text { w/o zone } 4\end{array}$ & 49,488 cells & $\mathrm{N} / \mathrm{A}$ \\
\hline
\end{tabular}


Table 6. Case 3 Summary of Grids and Time Steps (cont'd)

\begin{tabular}{|c|c|c|c|}
\hline Label & Girid type & Grid size & Time steps / cycle \\
\hline UMD-rans-sa-cent-2 & 2-D Structured (irid \#2 & 52.080 cells & 612 \\
\hline IMD-rans-sa-cent-2-3d & $\begin{array}{c}\text { 3-D Structured (irid } \\
\text { (half span) }\end{array}$ & 2.1 million cells & $N / A$ \\
\hline UMD-rans-sst-cent-2 & 2-D Structured Grid\#2 & 52,080 cells & $\mathrm{N} / \mathrm{A}$ \\
\hline UMD-rans-sa-cent-1 & 2-D Structured (irid\#1 & 208.320 cells & $\mathrm{N} / \mathrm{A}$ \\
\hline UMD-rans-sa-roe-2 & 2-D Structured Girid\#2 & 52,080 cells & 612 \\
\hline IMD-rans-sst-roe-2 & 2-D Structured Grid\#2 & 52,080 cells & $N / A$ \\
\hline US-fluent-ko & 2-D Instructured Cirid & 85.760 cells & $\mathrm{N} / \mathrm{A}$ \\
\hline IS-fluent-ke & 2-D Instructured Grid & 85.760 cells & $N / A$ \\
\hline IS-fluent-sa & 2-D Instructured Grid & 85.760 cells & $N / A$ \\
\hline ISG-fluent-sst & 2-D Instructured (irid & 85.760 cells & $N / A$ \\
\hline IS-fluent-v $2 \mathrm{f}$ & 2-D Unstructured Grid & 85.760 cells & $N / A$ \\
\hline
\end{tabular}

19 of 31 


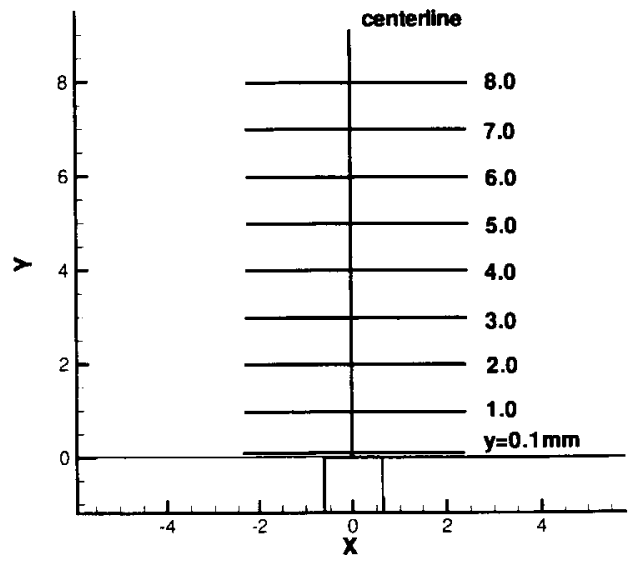

Figure 1. Sketch of the case 1 comparison locations.

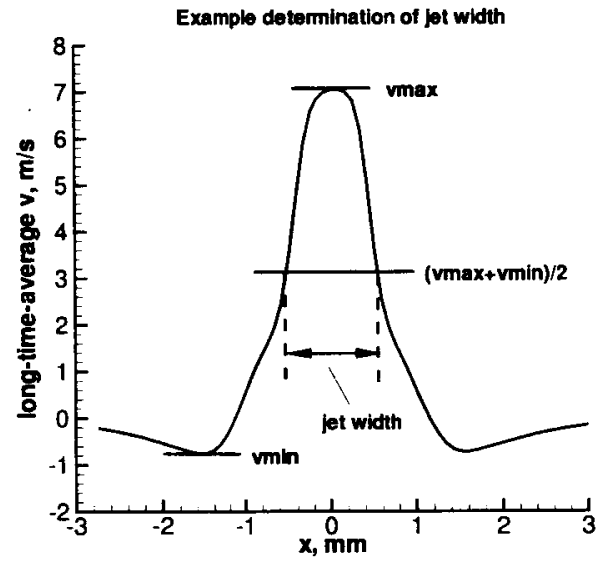

Figure 2. Sketch showing definition of jet width for case 1.
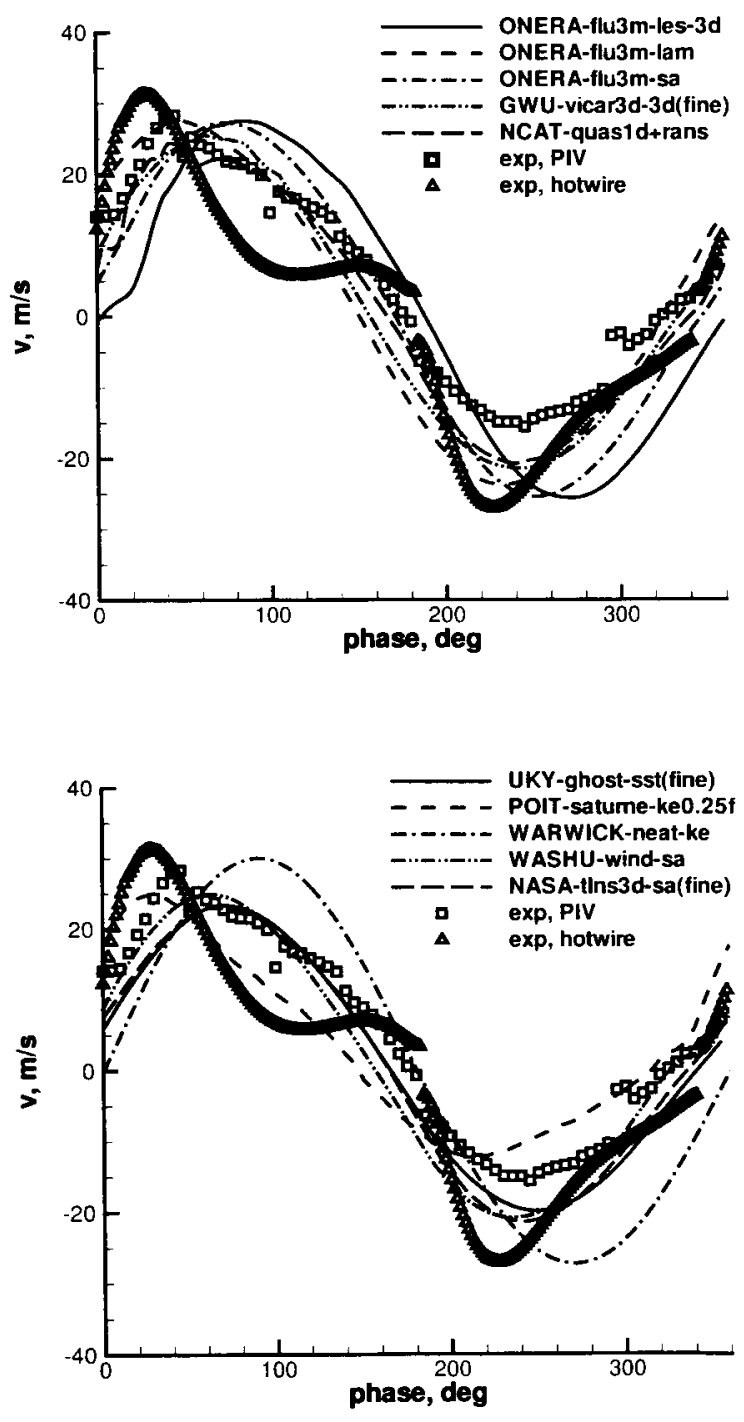

Figure 3. Case 1 time histories of v-velocity at $x=0$. $y=0.1 \mathrm{~nm}$. 

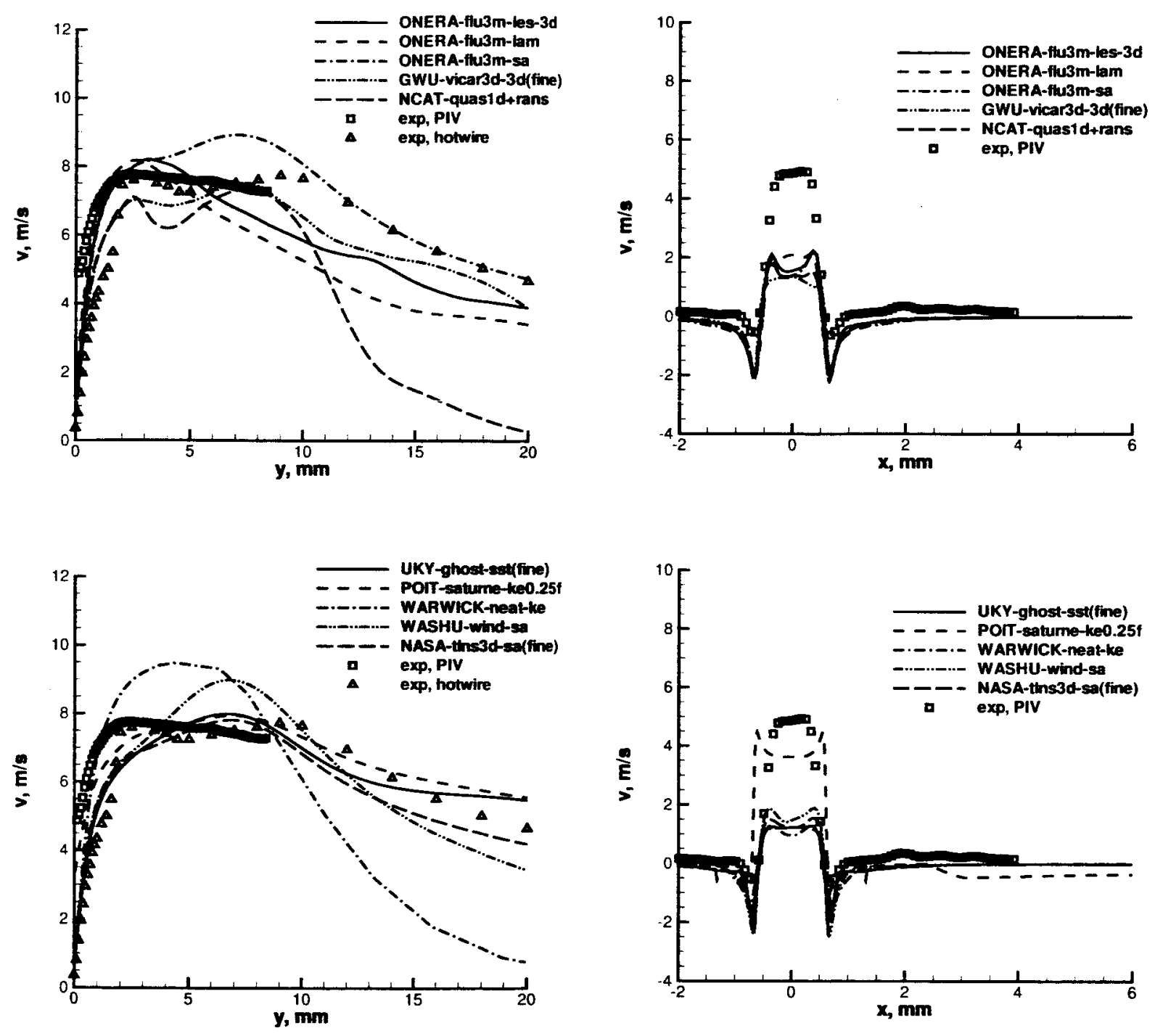

Figure 4. Case 1 average $v$-velocity profiles at $x=0$.

Figure 5. Case 1 average v-velocity profiles at $y=0.1 \mathrm{~mm}$.

21 of 31 

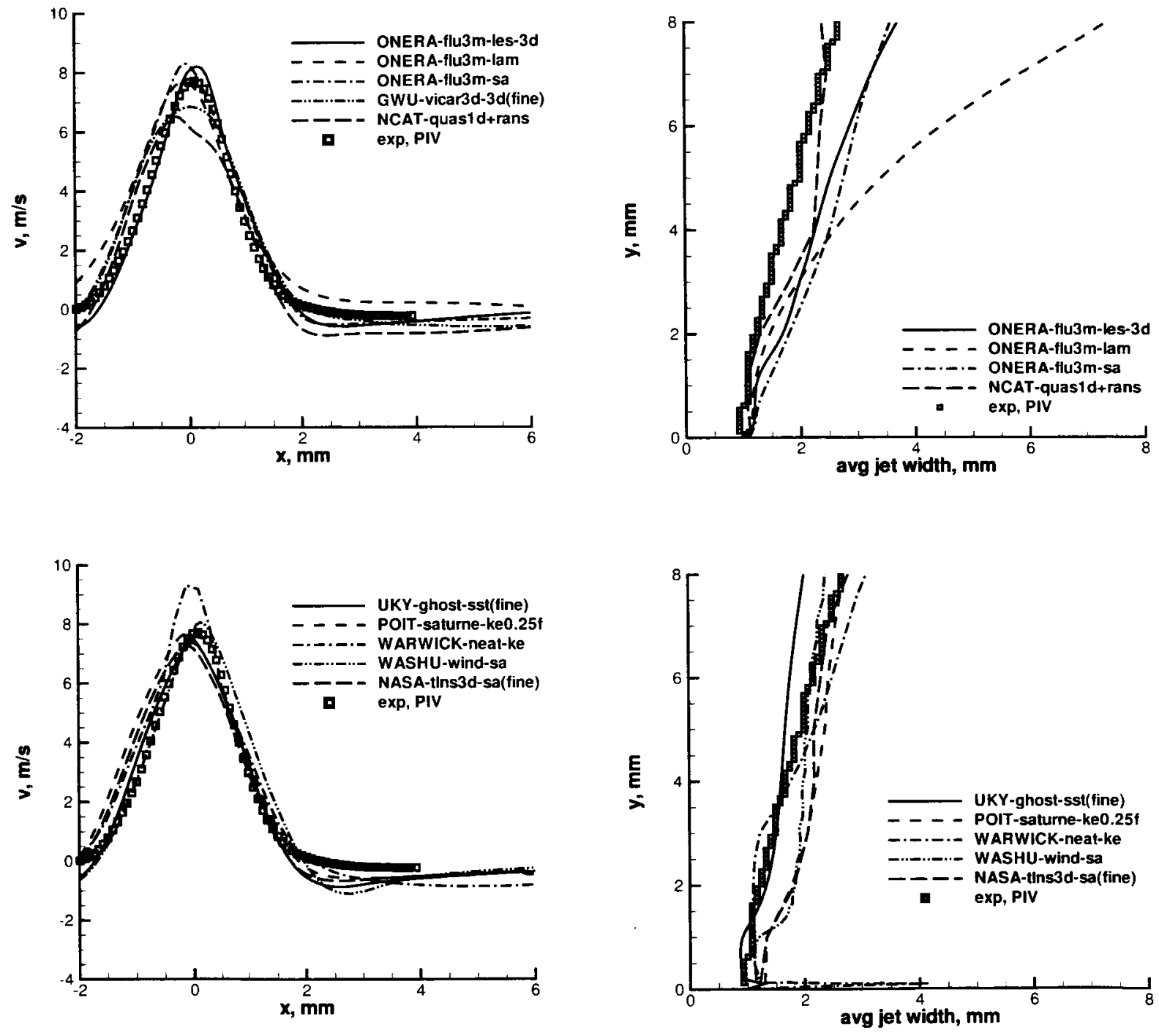

Figure 6. Case 1 average v-velocity profiles at $y=4 \mathrm{~mm}$.

Figure 7. Case 1 jet width based on average v-velocity. 

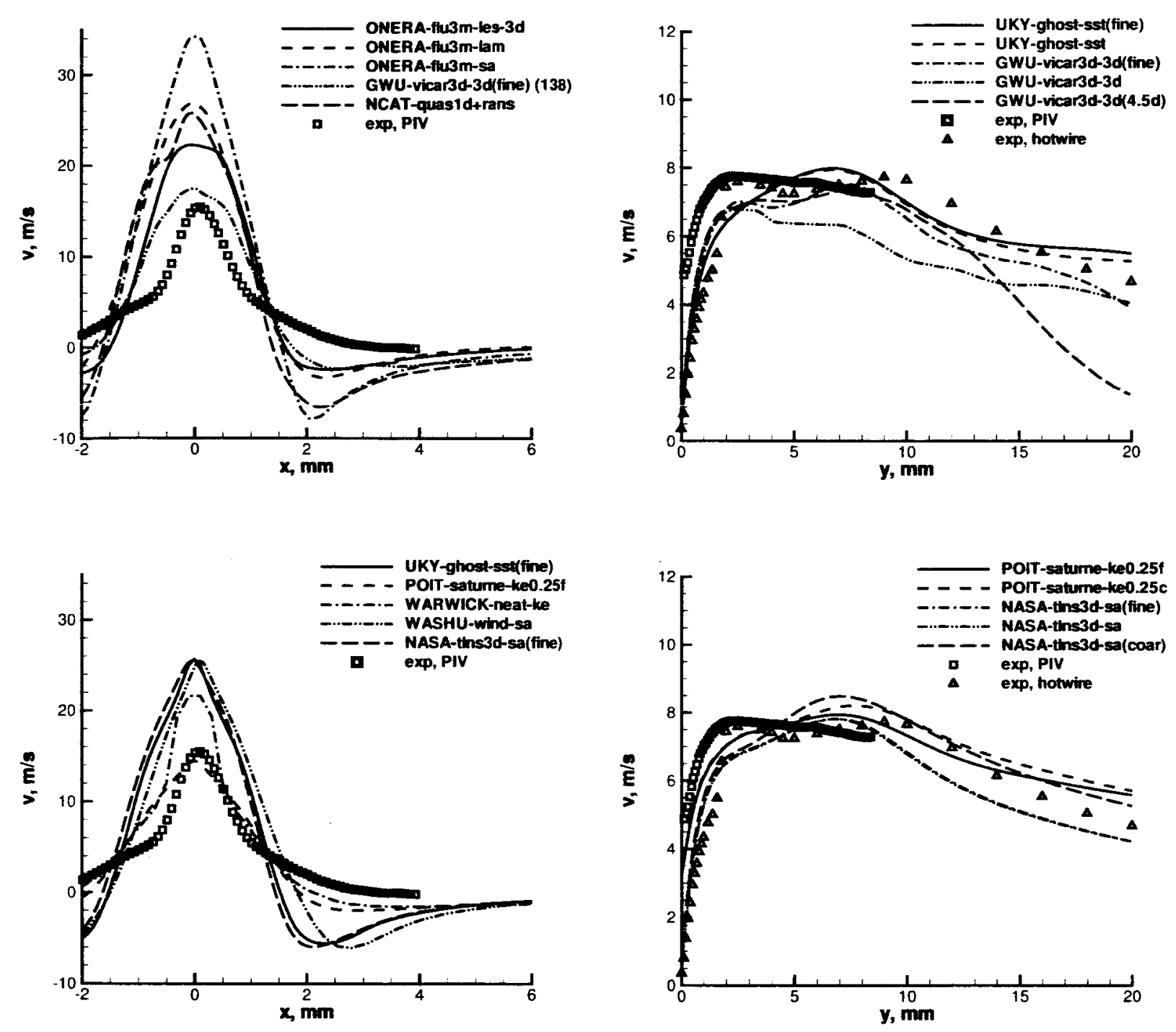

Figure 8. Case 1 phase-averaged v-velocity profiles at $\mathbf{y}=4 \mathrm{~mm}$, phase $=135^{\circ}$.

Figure 9. Grid effect on case 1 average $v$-velocity profiles at $x=0$. 

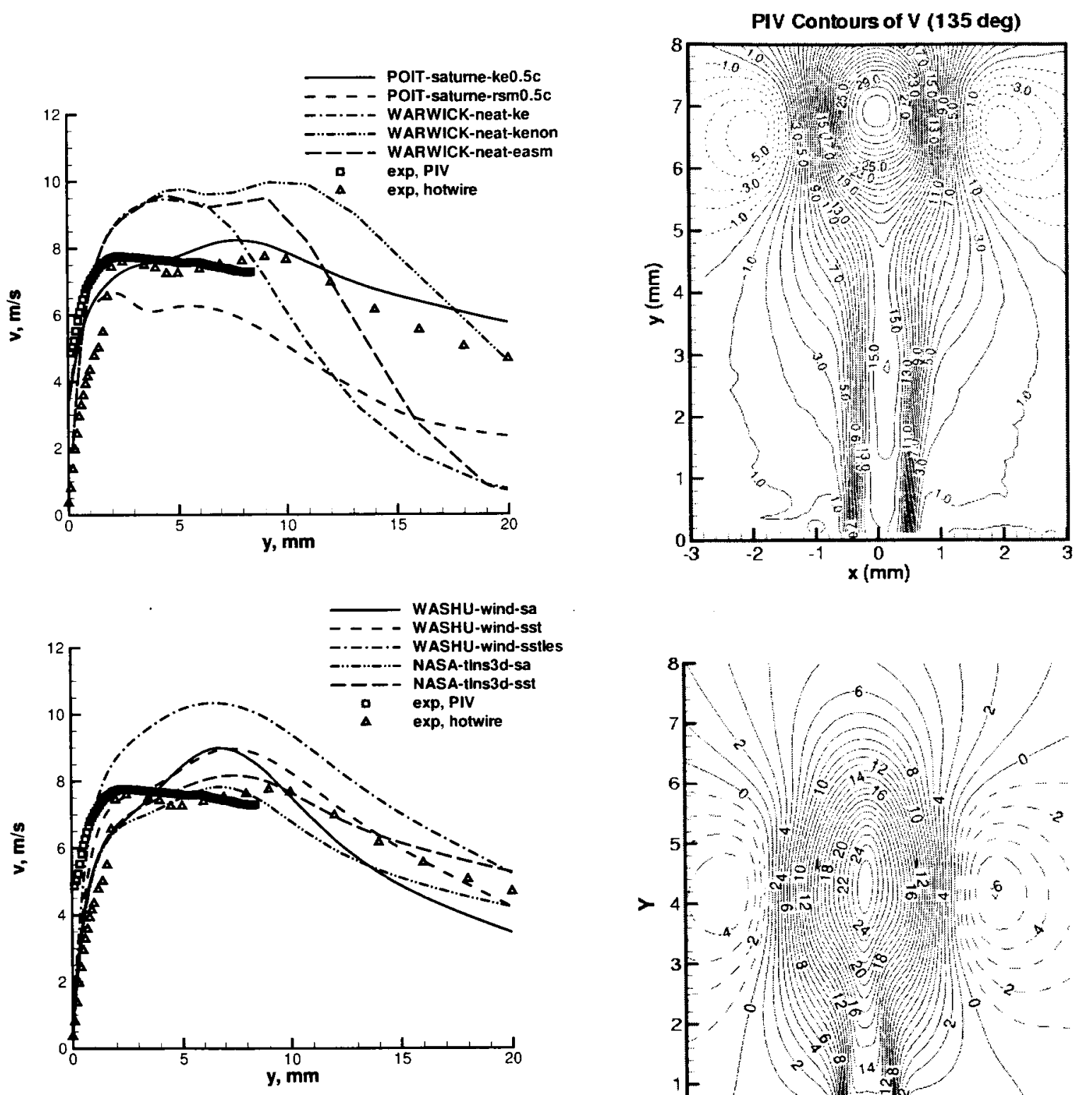

Figure 10. Turbulence model effect on case 1 average $v$-velocity profiles at $x=0$.

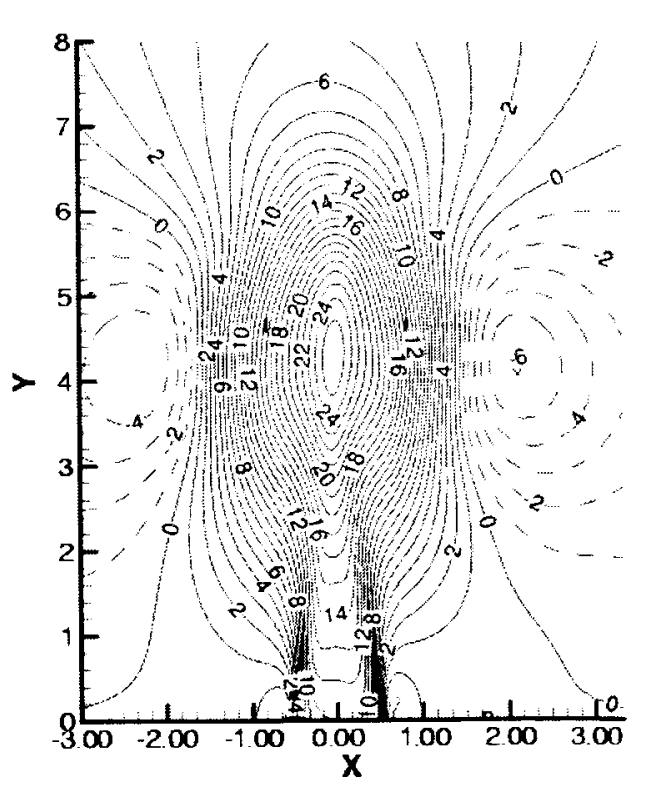

Figure 11. Case 1 contours of v-velocity, phase $=135^{\circ}$; (a) PIV experiment, (b), NASA-tlns3d-sa(fine). 

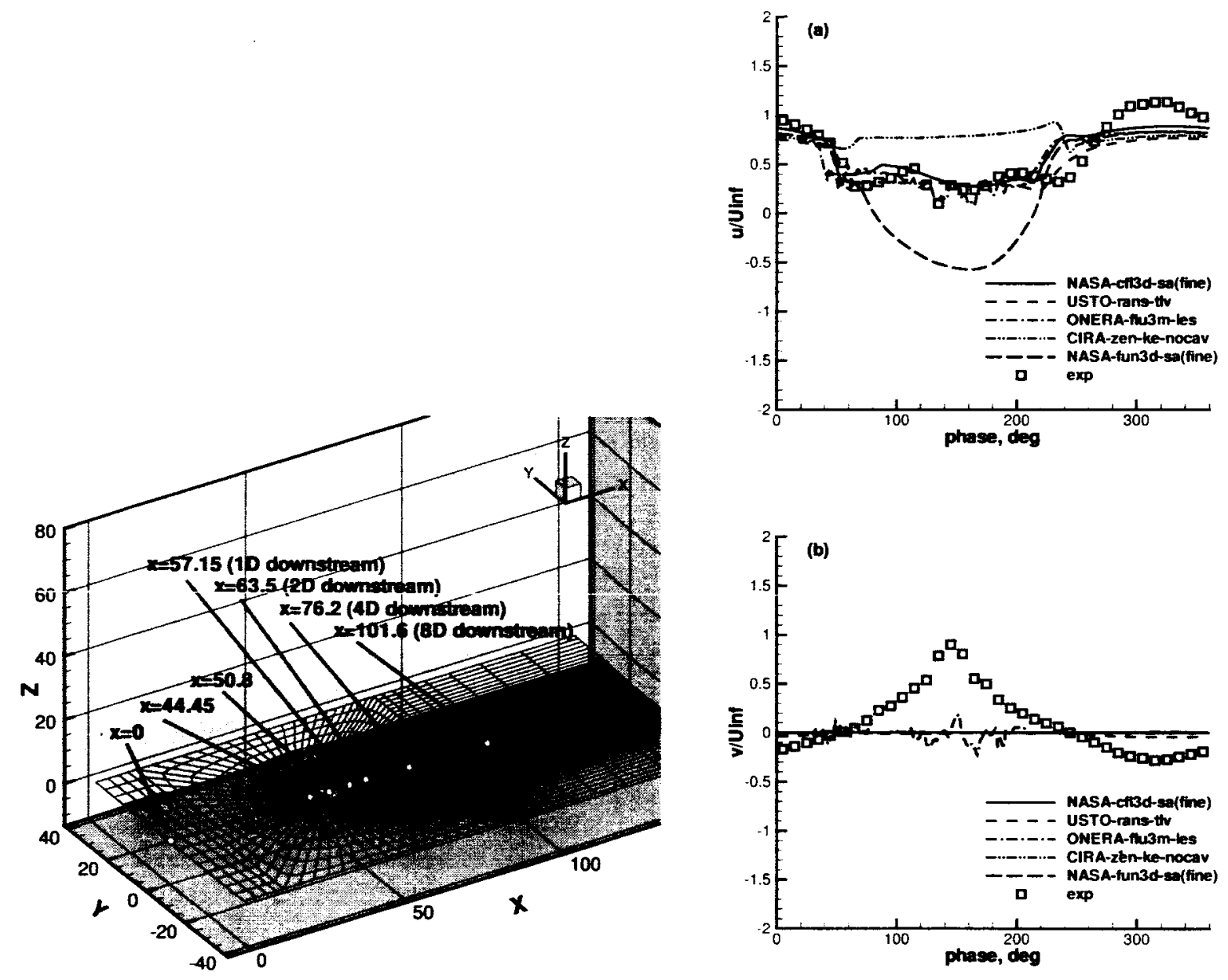

Figure 12. Sketch of some of the case 2 comparison locations.

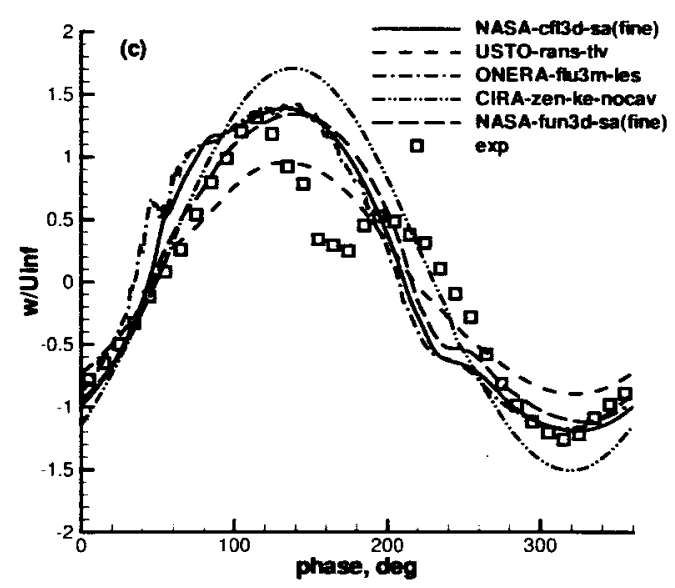

Figure 13. Case 2 time histories at $x=50.63 \mathrm{~mm}, y=0$. $z=0.4 \mathrm{~mm}$ : (a) $u$-velocity, (b) v-velocity. (c) w-velocity. 

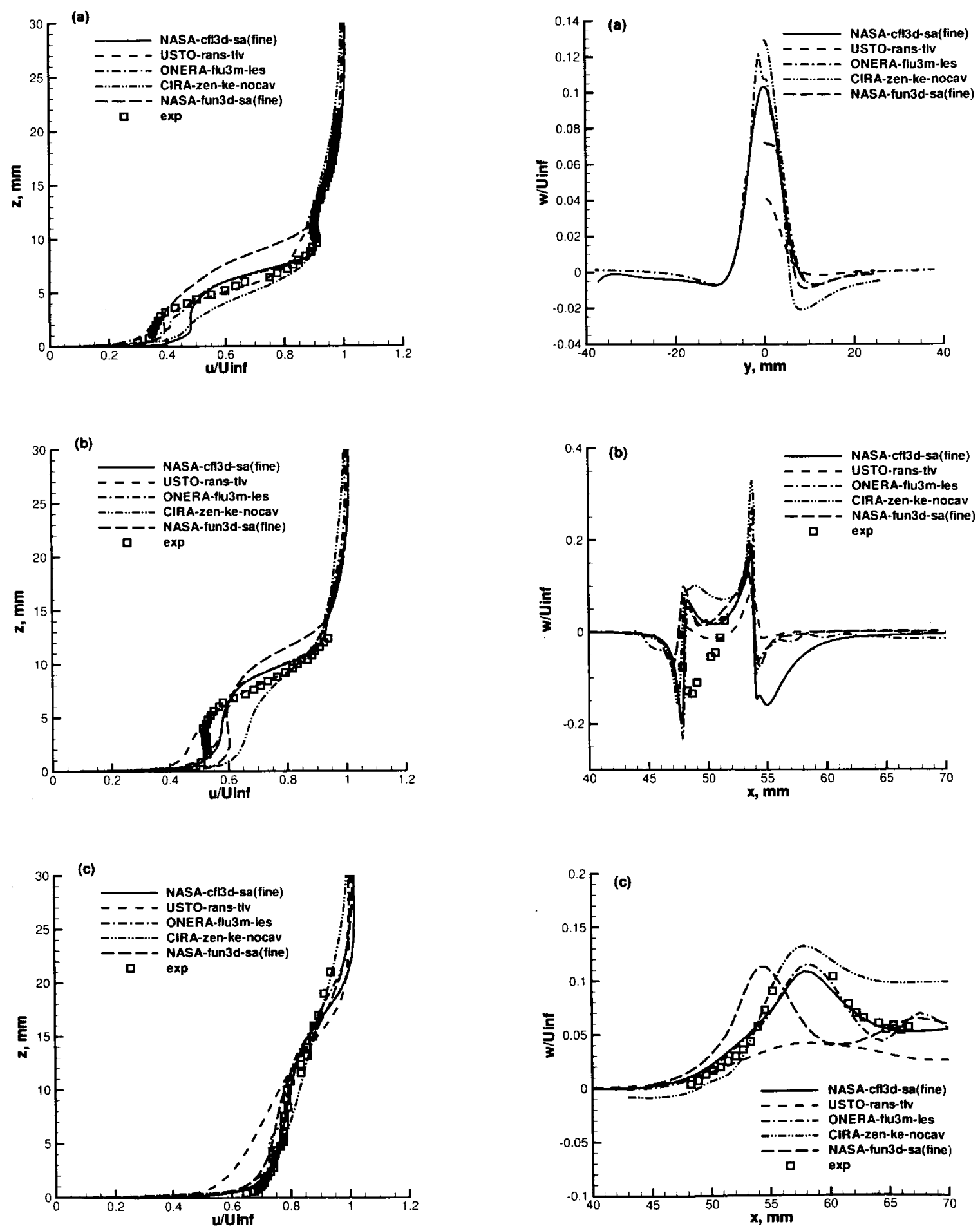

Figure 14. Case 2 average $u$-velocity at $y=0$; (a) $1 \mathrm{D}$ Figure 15. Case 2 average w-velocity; (a) $z=10 \mathrm{~mm} 1 \mathrm{D}$ downstream, (b) $2 \mathrm{D}$ downstream, (c) $8 \mathrm{D}$ downstream. downstream, (b) $\mathrm{z}=0.4 \mathrm{~mm}$ and $y=0$, (c) $\mathrm{z}=10 \mathrm{~mm}$ and $\mathbf{y}=0$.

$$
26 \text { of } 31
$$




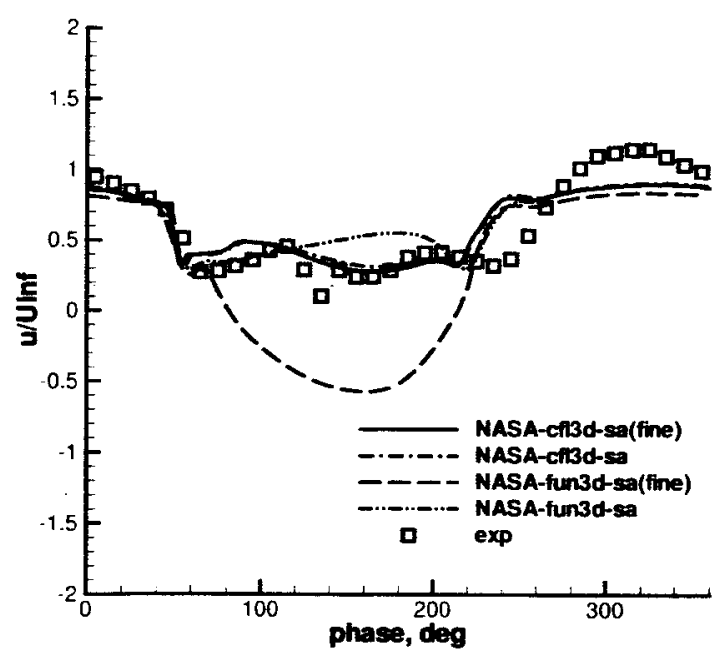

Figure 16. Grid effect on case 2 u-velocity time histories at $x=50.63 \mathrm{~mm}, y=0 . z=0.4 \mathrm{~mm}$.

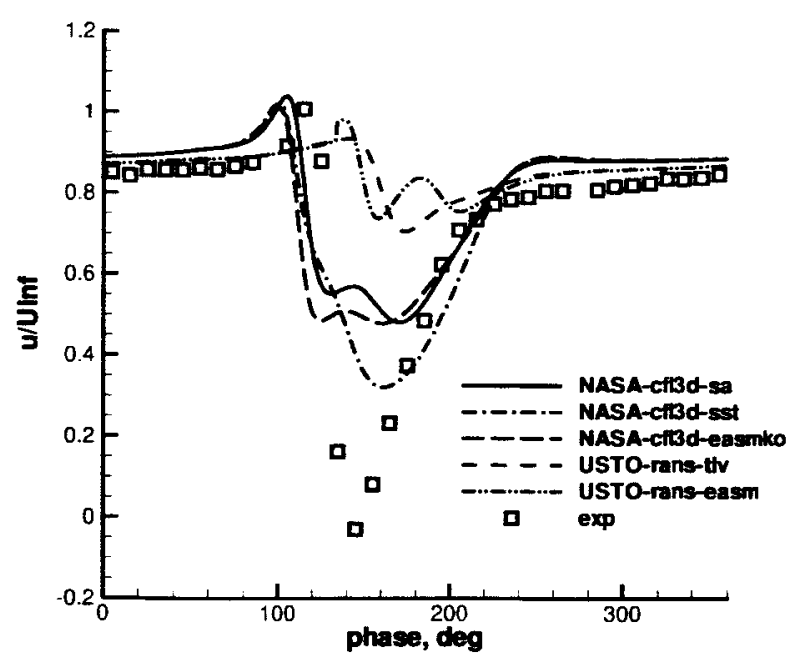

Figure 17. Turbulence model effect on case 2 uvelocity time histories at $x=63.5 \mathrm{~mm}, y=0, z=10 \mathrm{~mm}$.
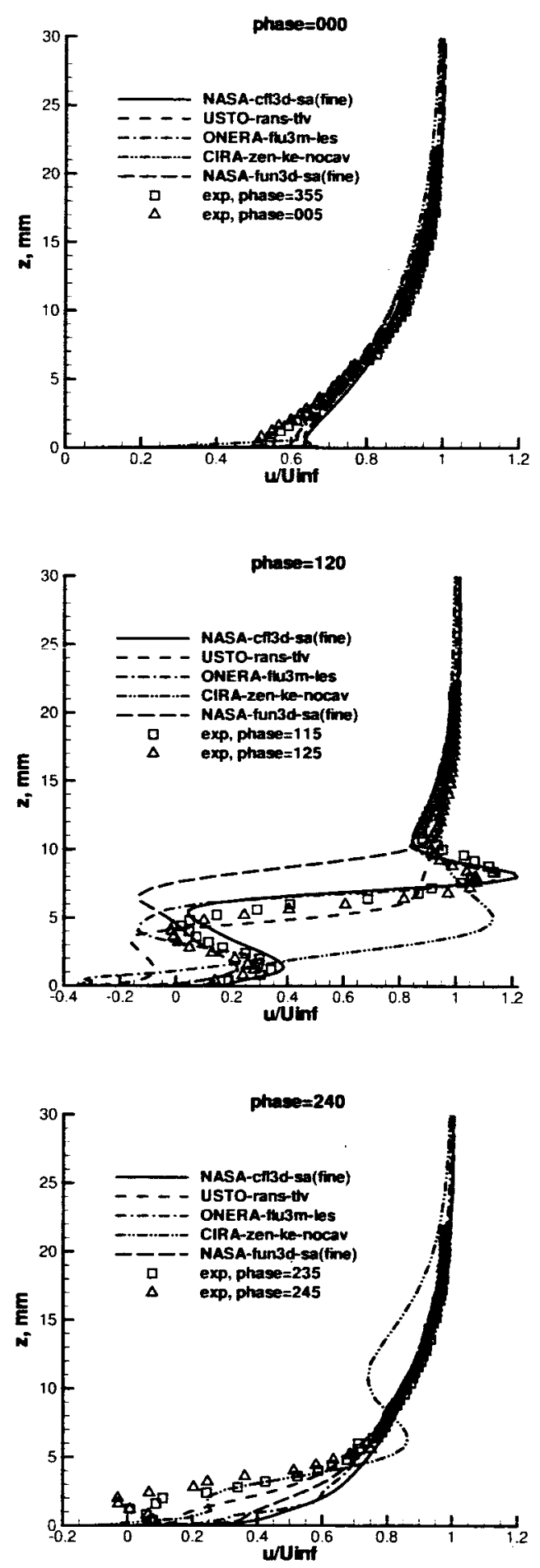

Figure 18. Case 2 phase-averaged $u$-velocity at $y=0$ and 1D downstream: (a) phase $=0^{\circ}$. (b) phase $=120^{\circ}$. (c) phase $=240^{\circ}$.

$2 \pi$ of 31 


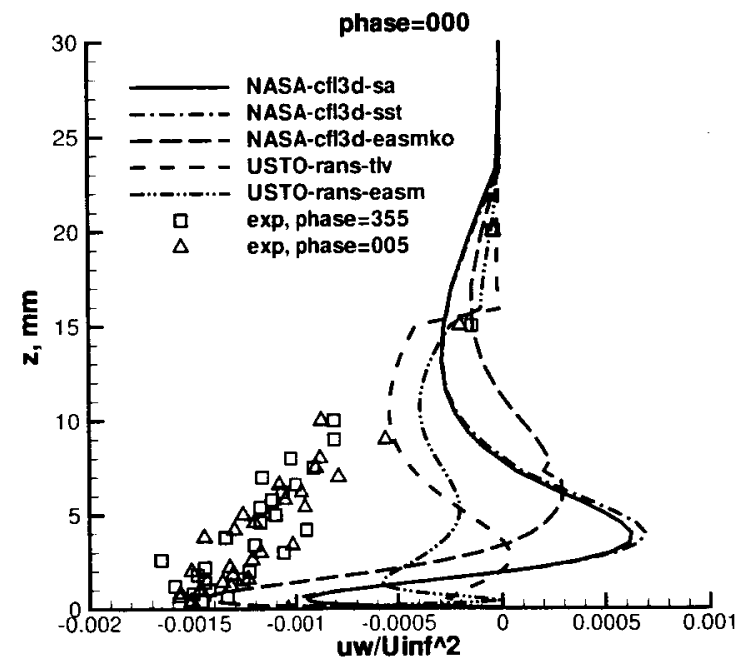

Figure 19. Turbulence model effect on case 2 phaseaveraged $u^{\prime} u^{\prime}$ turbulent stress at $x=44.45 \mathrm{~mm}$. $y=0$. phase $=0^{\circ}$.
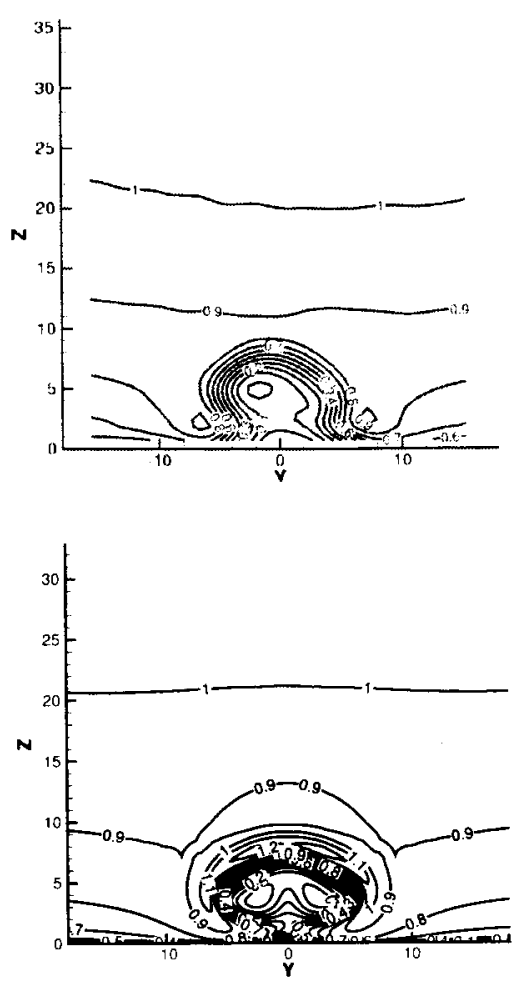

Figure 20. Example contours of phase-averaged nvelocity. 1D downstream. phase $=120^{\circ}$; (a) PIV experiment. (b) NASA-cfl3d-sa(fine).

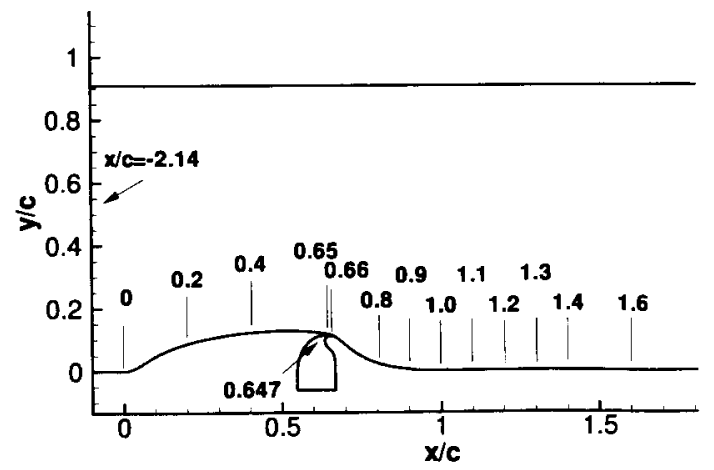

Figure 21. Sketch of the case 3 comparison locations. 

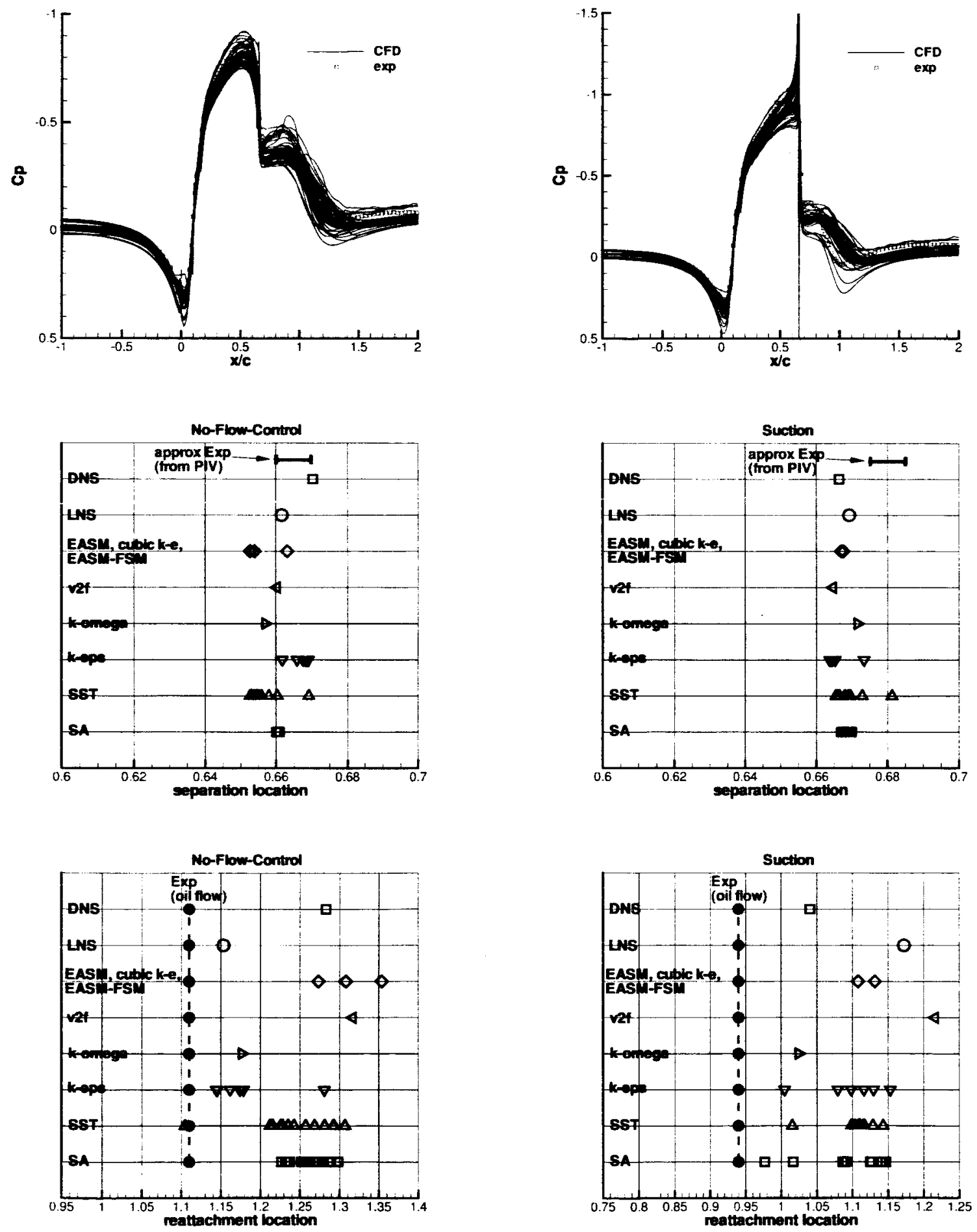

Figure 22. Summary of case 3 results compared to Figure 23. Summary of case 3 results compared to experimental data for no-flow-control condition; (a) experimental data for suction condition: (a) $(\bar{c}$, (b) $C p$. (b) separation location, (c) reattachment location. separation location. (c) reattachment location. 29 of 31 


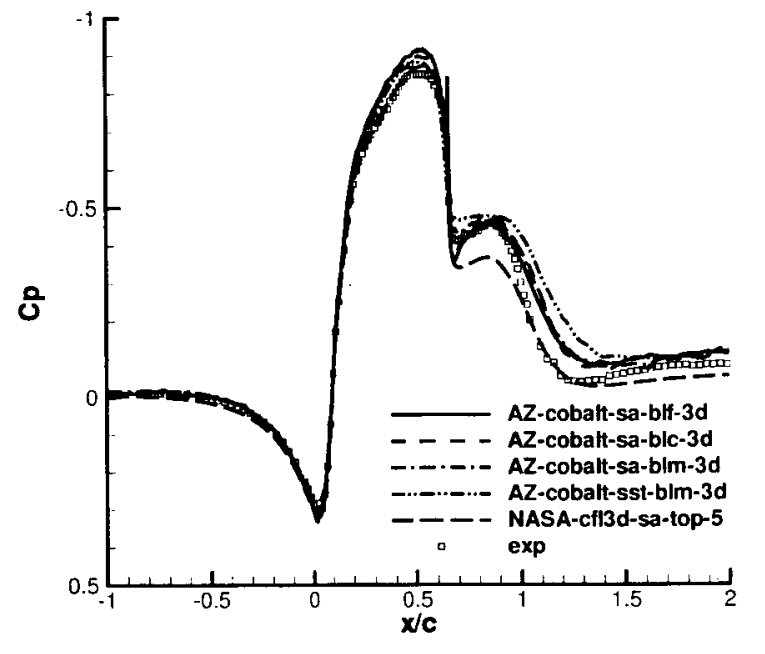

Fignre 24. Surface pressure coefficients for case 3 results that accounted for tunnel blockage.

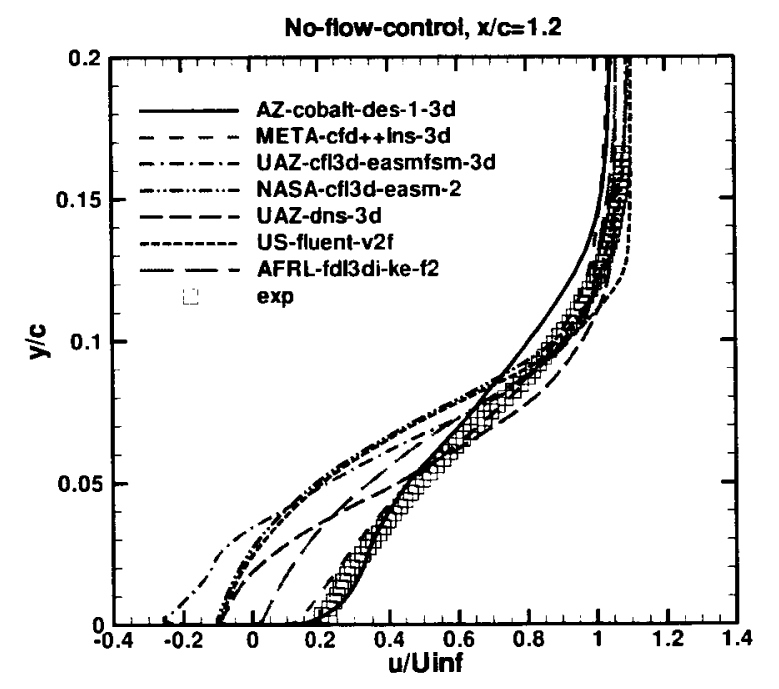

Figure 25. Sample of case 3 no-flow-control condition u-velocity profiles at $x / c=1.2$ (downstream of experimental reattachment).
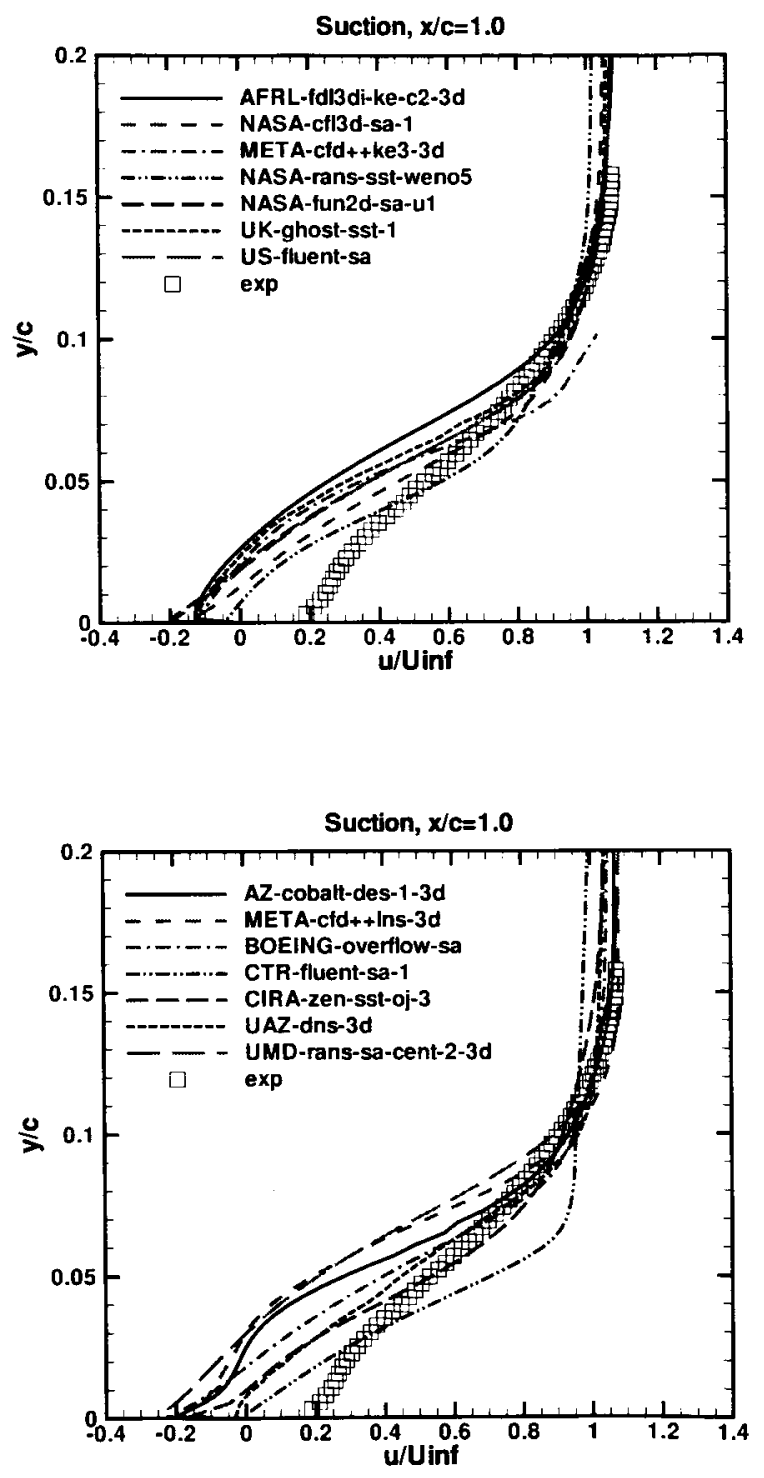

Figure 26. Sample of case 3 suction condition uvelocity profiles at $x / c=1.0$ (downstream of experimental reattachment). 

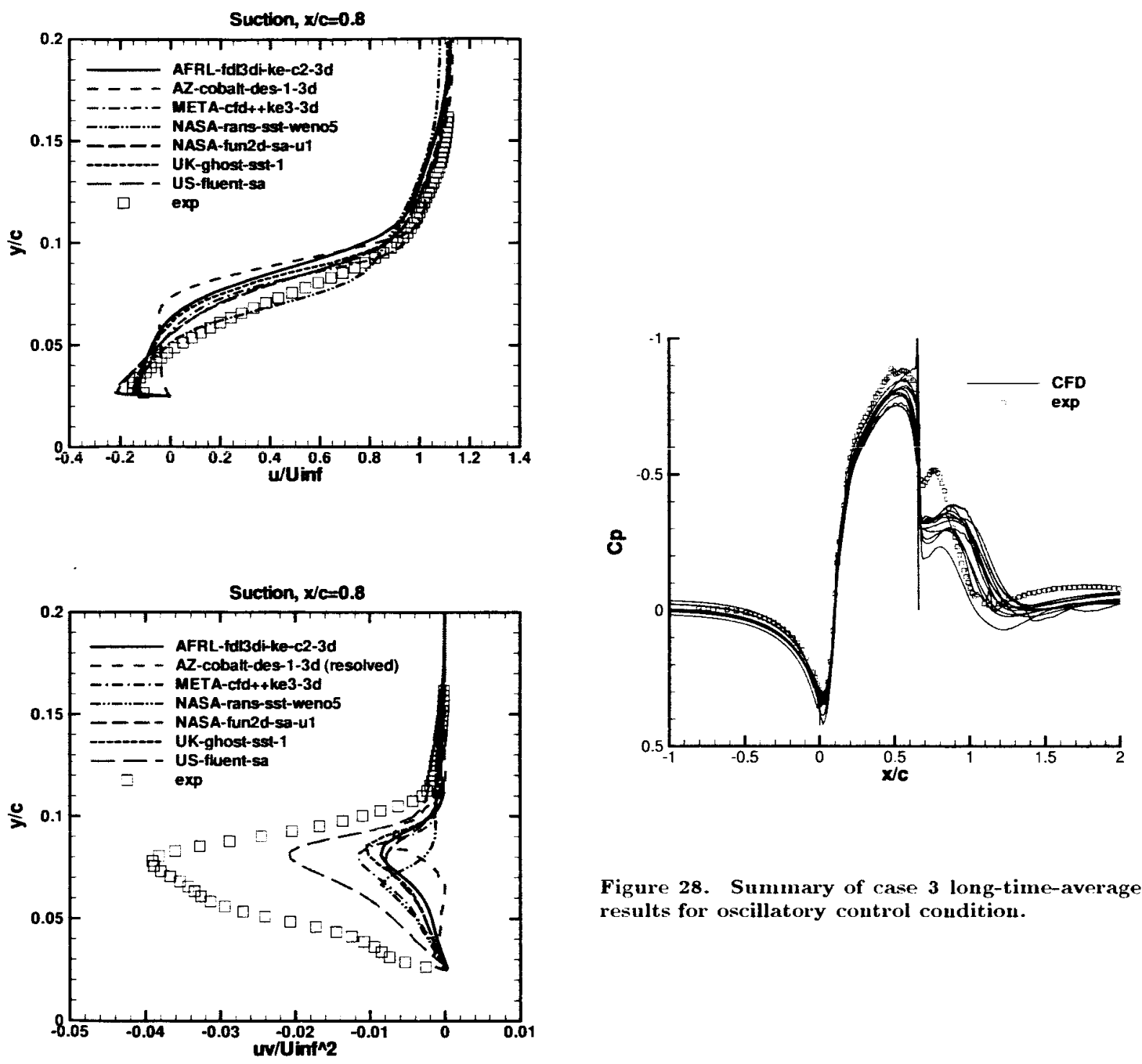

Figure 28. Summary of case 3 long-time-average $C_{P}$ results for oscillatory control condition.

Figure 27. Sample of case 3 suction condition results at $x / c=0.8$ (inside separation bubble); (a) u-velocity, (b) turbulent shear stress. 